\title{
The Belgian Bone Club 2020 guidelines for the management of osteoporosis in postmenopausal women
}

Authors: Sanchez-Rodriguez $\mathrm{D}^{1,2}$; Bergmann $\mathrm{P}^{3}$; Body $\mathrm{JJ}^{4}$; Cavalier $\mathrm{E}^{5}$; Gielen $\mathrm{E}^{6}$; Goemaere $\mathrm{S}^{7}$; Lapauw $\mathrm{B}^{7}$; Laurent $\mathrm{MR}^{8}$; Rozenberg $\mathrm{S}^{9}$; Honvo $\mathrm{G}^{1}$; Beaudart $\mathrm{C}^{1}$; Bruyère $\mathrm{O}^{1}$.

\section{Affiliations:}

1. WHO Collaborating Center for Public Health aspects of musculo-skeletal health and ageing, Division of Public Health, Epidemiology and Health Economics, University of Liège, Liège, Belgium

2. Geriatrics Department, Rehabilitation Research Group, Hospital del Mar Medical Research Institute (IMIM). Universitat Pompeu Fabra, Barcelona, Spain.

3. Department of Radioisotopes, CHU Brugmann, Université Libre de Bruxelles, Brussels, Belgium.

4. Department of Medicine, CHU Brugmann, Université Libre de Bruxelles, Brussels, Belgium.

5. Department of Clinical Chemistry, UnilabLg, University of Liège, CHU de Liège, Liège, Belgium.

6. Gerontology and Geriatrics Section, Department of Chronic Diseases, Metabolism and Ageing (CHROMETA), KU Leuven, University Hospitals, Leuven, Belgium.

7. Unit for Osteoporosis and Metabolic Bone Diseases, Ghent University Hospital, Ghent, Belgium.

8. Geriatrics Department, Imelda Hospital, Bonheiden, Belgium.

9. Department of Gynaecology-Obstetrics, Université Libre de Bruxelles, Brussels, Belgium. 
Corresponding author: Dolores Sanchez-Rodriguez MD PhD

WHO Collaborating Center for Public Health aspects of musculo-skeletal health and ageing, Division of Public Health, Epidemiology and Health Economics, University of Liège, CHU - Sart Tilman. Quartier Hôpital Avenue Hippocrate 13 (Bât. B23), 4000 Liège, Belgium. Tel: +3243662519.

E-mail: dolores.sanchez@uliege.be

Authors' contribution: DSR, CB, and OB wrote the manuscript; GH and CB conducted the literature search strategy; DSR and OB did literature review; ML, LL, and CB participated in data collection; PB, JJB, EC, EG, SG, BL, MRL, SR, and OB corrected the manuscript through consecutive comment rounds. All co-authors read and approved the final version of the manuscript. 


\title{
The Belgian Bone Club 2020 guidelines for the management of osteoporosis in postmenopausal women
}

Summary: Updated evidence-based guidance is provided for the screening, diagnosis, treatment and monitoring of osteoporosis in postmenopausal women in Belgium.

\begin{abstract}
Purpose: To provide updated evidence-based guidelines for the management of osteoporosis in postmenopausal women in Belgium.

Methods: The Belgian Bone Club (BBC) gathered a guideline developer group. Nine “Population, Intervention, Comparator, Outcome” (PICO) questions covering screening, diagnosis, non-pharmacological and pharmacological treatments, and monitoring were formulated. A systematic search of MEDLINE, Cochrane Database of Systematic Reviews, and Scopus was performed to find network meta-analyses, meta-analyses, systematic reviews, guidelines, and recommendations from scientific societies published in the last 10 years. Manual searches were also performed. Summaries of evidence were provided, and recommendations were further validated by the BBC board members and other national scientific societies’ experts.
\end{abstract}

Results: Of the 3,840 references in the search, 333 full texts were assessed for eligibility, and 129 met the inclusion criteria. Osteoporosis screening using clinical risk factors should be considered. Patients with a recent ( $<2$ years) major osteoporotic fracture were considered at very high and imminent risk of future fracture. The combination of bone mineral density measured by dual-energy X-ray absorptiometry and 10-year fracture risk were used to categorize patients as low or high risk. Patient education, the combination of weight-bearing and resistance training and optimal calcium intake and vitamin D status were recommended. Antiresorptive and anabolic osteoporosis treatment should be considered for patients at high and very high fracture risk, respectively. Follow-up should focus on compliance, and patient-tailored monitoring should be considered.

Conclusion: BBC guidelines and 25 guideline recommendations bridge the gap between research and clinical practice for the screening, diagnosis, and management of osteoporosis.

Keywords: Belgian Bone Club; osteoporosis; postmenopausal women; diagnosis; treatment; guidelines. 


\section{BACKGROUND}

Osteoporotic fractures are a major cause of functional impairment, disability, pain, and mortality. However, the incidence and intensity of these adverse outcomes might be reduced if targeted state-of-the-art management of osteoporosis is applied. Comprehensive guidelines in osteoporosis should include recommendations about screening, diagnosis, treatment, and monitoring to allow their implementation in clinical practice [1]. Moreover, there is a need for country-specific guidelines because of differences in the epidemiology of the disease, health-care costs, and healthcare systems among countries.

The Belgian Bone Club (BBC) is a multidisciplinary group of professionals that aims to address current unmet needs and improve quality of care for patients with osteoporosis and other metabolic bone diseases in Belgium (http://www.bbcbonehealth.org/). Herein, we provide an updated version of the previous BBC guidelines published in 2010 [2]. This update is necessary because new evidence has become available.

\section{OBJECTIVE}

Our objective was to develop updated evidence-based guidelines for the screening, diagnosis, and management of osteoporosis in postmenopausal women in Belgium.

\section{METHODS}

The BBC gathered a multidisciplinary group of specialists in clinical chemistry, endocrinology, epidemiology, gerontology and geriatrics, gynecology, internal medicine, nephrology, radiology, rheumatology, physiotherapy, primary care, and public health focused on updating the current existing guidelines for the management of postmenopausal osteoporosis [2]. The target end-users are primary care physicians as well as specialists involved in osteoporosis care in Belgium.

Population, Intervention, Comparator, Outcome (PICO) questions: Nine PICO questions covering screening, diagnosis, non-pharmacological and pharmacological treatments, monitoring, etc. were formulated and discussed among the BBC board members for approval (Table 1S).

The BBC Guidelines Developer Group was composed of:

- A Working Group (CB, DSR, GH, OB) to propose a methodology, draft the 9 PICO questions, review the literature, and draft the synthesis of the literature. 
- An Expert Panel (the Working Group and the BBC board members) to supervise the scope, draft the PICO questions, modify and approve the synthesis of the literature, propose recommendations and supervise the implementation of the project.

- A Voting Panel (8 BBC board members, and 28 Belgian expert clinicians selected by the $\mathrm{BBC}$ board to vote on the final recommendations.

The Working Group decided to focus the literature search on network meta-analyses (NMA), meta-analyses (MA), systematic review (SR), guidelines and recommendations from scientific societies. This choice was made because NMA, MA, and SR are considered the highest level of categories of evidence [3]. A preliminary search confirmed that at least one MA or SR was available for each PICO question. This preliminary search found a substantial number of guidelines and recommendations: The Working Group decided to focus the search on guidelines from international scientific societies, the United States, and European countries, whose sociodemographic characteristics and perspective were considered most likely to be similar to those of Belgium.

Systematic literature search: The Preferred Reporting Items for Systematic Reviews and Meta-Analyses (PRISMA) statement was followed [4]. The 9 PICO questions (Table 1S) were used to conduct the literature search in MEDLINE (via Ovid), the Cochrane Database of Systematic Reviews (Ovid CDSR), and Scopus to find articles published in the last 10 years, since the publication of the current existing guidelines for the management of osteoporosis in Belgium [2]. NMA, MA, SR, and recommendations from scientific societies were identified. The search strategy was built, including the terms “Osteoporosis” AND (SR/MA OR “guideline”), and was limited to the period from 01/01/2010 to 22/06/2019 (Table 2S). The language was limited to English for pragmatic reasons. A manual search in the reference section of the selected papers and in the websites of the World Health Organization (WHO), the International Classification of Diseases (ICD), the International Osteoporosis Foundation (IOF), the European Medicines Agency (EMA), the European Society for Clinical and Economic Aspects of Osteoporosis, Osteoarthritis, and Musculoskeletal Diseases (ESCEO), and the BBC was performed to find additional information and more recent original studies if they were considered relevant. The Expert Panel was free to propose additional references, regardless of the study design, to answer the research questions. 


\section{Eligibility criteria}

\section{Inclusion criteria}

- SR and/or MA about screening, monitoring or diagnostic tools in postmenopausal women diagnosed/at risk of osteoporosis (PICO 1-4 and 7-9).

- NMA and MA about the efficacy of pharmacological treatments, calcium, and vitamin D that include placebo-controlled studies and that have fracture as an outcome. Pharmacological interventions were selected on the basis of the National Institute of Health and Care Excellence recommendations regarding the drugs available for treating osteoporosis in Belgium (alendronate, bazedoxifene, denosumab, ibandronate, menopausal hormone therapy, raloxifene, risedronate, teriparatide, and zoledronate), combination therapy, and the investigational treatments abaloparatide and romosozumab (PICO 5-6).

- MA about the safety of pharmacological treatments, calcium, and vitamin D (all study designs and all outcomes were allowed for safety) (PICO 5-6).

- MA about physical activity in osteoporosis that have fracture, effects on BMD, physical function, activities of daily living (ADL), and falls as outcomes (PICO 5).

- Guidelines and recommendations from international scientific societies, the United States, and European countries (PICO 1-9).

\section{Exclusion criteria}

Studies on the following topics were excluded: acute fracture care, high-energy fractures, fracture healing, surgery and dental procedures, secondary osteoporosis, male sex, glucocorticoid-induced, cancer therapy-induced or premenopausal osteoporosis, and studies in languages other than English.

All references were first screened on title/abstract by two independent reviewers (DSR and $\mathrm{OB}$ ) who decided to include or exclude references based on the eligibility criteria. Interrater agreement was calculated to verify that the eligibility criteria were applied correctly and to increase the quality of the search. The two independent reviewers screened and discussed together the first 100 references. Agreement between the two reviewers was determined with kappa (k) statistics, where 0.81-1 was considered almost perfect agreement [5]. The results showed almost perfect agreement $(k=0.826$, asymptotic standard error 0.098, $\mathrm{p}=0.000$ ). A consensus was reached for the 3 articles 
about which the 2 reviewers disagreed. The rest of the references were screened by the two reviewers independently.

Selection of the full texts of the articles retrieved from the screening was also performed by the two independent reviewers. Any discrepancies of opinion between the two reviewers were solved by discussion and consensus and by the intervention of a third reviewer (CB) if necessary. Reasons for the exclusion of full-text papers were collected.

Summaries of Evidence: According to the Oxford Centre for Evidence-Based Medicine Standards [3], we prioritized data from NMA, then MA, then SR, and then the guidelines. For pharmacological treatments, we were interested in evidence of their efficacy but also in their safety, with effect sizes where available. For screening and diagnosis tools, we were interested in metrological properties, benefits, and harms, if available. The different types of physical activity were categorized according to the Prevention of Falls Network Europe project (ProFANE) taxonomies for physical activity interventions [6]. For guidelines, if more than one edition was available (same society and topic), the most updated version was selected. The best evidence retrieved from the literature review was written as a summary of evidence for each PICO question, and a first draft was sent to the Expert Panel. Comments from the panel about the summaries and additional studies provided by the panel were taken into account and compiled into a final version.

Recommendations: The Working Group prepared a draft for the recommendations that was modified by the Expert Panel through repeated comment rounds. The proposed recommendations were proposed to the Voting Panel by e-mail, asking the Voting Panel to vote on the recommendations considering benefits/risks, balance, cost (if possible), and their values and preferences.

Each recommendation was presented with the question: Do you agree with the recommendation?” and 4 possible answers: “Strong do, Weak do, Weak don’t, and Strong don't”. There was also a possibility to abstain due to a conflict of interest or insufficient expertise to judge a recommendation. Consensus on each recommendation (in favour or against) was defined as at least $75 \%$ of the Voting Panel being either "weak" or "strong" in favour of or against a recommendation. If this criterion was not met, a consensus was not reached, and no recommendation was made. The strength of a recommendation was determined as "strong" if at least $75 \%$ of the Voting Panel 
members rated a recommendation as "strong". After the voting process, a summary of all votes was obtained. The manuscript was drafted by the Working Group and shared with the Expert Panel for review through repeated comment rounds. All read and approved the final version of the manuscript before submission.

\section{Conflicts of interest (COI)}

A specific strategy to avoid COI among BBC board members, Expert, and Voting Panel members was applied. All COI were collected prospectively, and those members with any COI relevant to a specific question were asked not to vote on that topic.

\section{RESULTS}

The search strategy identified 5,196 references, which resulted in 3,840 studies after deleting duplicates obtained from the three databases. Following screening based on titles and abstracts according to the eligibility criteria, 333 papers were selected. After screening the full texts, 129 articles matched the inclusion criteria: 11 NMA [7-17], 79 MA [18-96], 12 SR [97-108], and 27 guidelines [1,2,109-133]. The reasons for the rejection of the 204 full-text articles have been detailed (Figure 1). One-hundred-fifteen articles [6,134-247] were included from the manual search.

\section{Q1. HOW should osteoporosis be screened in postmenopausal women?}

Two MA [19,26], 3 SR [99,105,107], 7 guidelines [1,111,112,118,120,128,132], and 1 articles from the manual search [194] contained relevant information for this PICO question.

The SR and MA showed that more than 15 screening questionnaires composed of a varying number of clinical risk factors have been published. The diagnostic accuracy (i.e., sensitivity and specificity) of the screening tools for osteoporosis varied depending on the target populations assessed. However, none of the tools performed consistently better than the others [26,105], and the number of risk factors assessed did not substantially influence performance, as questionnaires with more or fewer risk factors performed the same $[19,99]$. Moreover, most of the risk assessment tools presented methodological issues and potentially lacked external validity outside of the cohorts in which they were developed [107]. Therefore, insufficient evidence was found to recommend a particular osteoporosis screening tool over others. 
Two challenges underlie this lack of conclusive results: 1/ the existing tools assess different clinical outcomes, i.e., risk of low bone mineral density or risk of fracture [99,111]; and 2/ the existing assessment tools do not exhibit a clear difference between their screening and diagnostic capabilities. These two terms are used indistinctly, and the lack of unified terminology may produce contradictory recommendations. For example, dual-energy X-ray absorptiometry (DXA) is considered a screening or diagnostic tool depending on the guideline assessed [111,112,132]. However, the screening and diagnosis of osteoporosis are considered different categories by the International Classification of Diseases 10 (ICD-10) and the World Health Organization (WHO) strategy, which recommend a two-step process to identify the disease: first, identification of risk factors, as a sensitive strategy for screening in large populations, and second, a diagnostic procedure using high specificity measurements from billable, technical devices that is applied in the population selected by the screening. The recommendations in the European guidance are aligned with the WHO's strategy: risk factors are enumerated without mentioning any screening tool. Those women screened positively based on the presence of one or more risk factors should undergo a formal fracture risk evaluation (see Q3 and Q4).

The major risk factors considered by the European guidance [1] and in the 7 guidelines $[1,111,112,118,120,128,132]$ were the following: age ( $\geq 65$ years), low body mass index $\left(<20 \mathrm{~kg} / \mathrm{m}^{2}\right)$, prior fragility fractures, hip fracture history in a first-degree relative, measured height loss $\geq 4 \mathrm{~cm}$, secondary osteoporosis, early non-substituted menopause ( $<45$ years), diabetes mellitus, glucocorticoid therapy, rheumatic inflammatory diseases, and excessive alcohol ( $\geq 3$ units of alcohol/day) and/or current tobacco use. Frequent falls $(\geq 1 /$ year) are a major risk factor for fractures and an indication for a formal assessment of fracture risk. An assessment of fall risk was also recommended in all guidelines assessed [1,111,112,118,120,128,132]. Additional risk factors were identified (Table 3S). Postmenopausal women with $\geq 1$ major risk factor or $\geq 2$ additional risk factors could be suitable to undergo a formal fracture risk evaluation.

A list of the main risk factors is provided in the International Osteoporosis Foundation Risk Check. The Risk Check is self-administered and could be an option for raising awareness among patients and an effective communication tool for patients and clinicians. For example, it could be placed in the waiting room of a specialist or primary care physician. The Risk Check is available on the IOF and the BBC websites. 


\section{Q2. WHEN and HOW OFTEN should postmenopausal women be screened for osteoporosis?}

One MA [26], 2 SR [99,107], 10 guidelines [1,2,110-112,114,118,123,124,132], and 6 articles found by manual search [134,161,162,185,192,198] contained relevant information for this PICO question about the first screening and optimal interval for rescreening in women with negative results during the screening process and in those who obtain positive results in the screening but do not meet the criteria for diagnosis afterwards.

Optimal age for screening: The European guidance recommends screening at an age that should be fixed according to country-specific cost-effective thresholds [1]. In Belgium, no cost-effective threshold has been evaluated. Most of the European National guidelines have considered 50 years the optimal age threshold for first screening: United Kingdom [132], Greece [124], Poland [110], and Portugal [123]. A brief mention about an age of 50 years appears in the previous BBC 2010 guidelines [2] and in the BBC consensus about non-pharmacological management of osteoporosis [114]. Even if individual studies have suggested that screening at an age of 65 or over could be more relevant, most of the studies included in two SR that assessed the performance of risk assessment instruments to predict fracture risk included participants $\geq 50$ years $[99,107,185]$. Despite the low level of evidence, an age threshold of 50 years could still be an adequate option in Belgium. It is important to note that menopause is not a point on the time but a progressive process of menopausal transition during which bone loss starts before the complete cessation of the menses [192]. Screening (by identification of risk factors, as outlined in Q1) at the age of 50 years, or at the age of menopause if it occurs earlier, should be considered.

Optimal interval for re-screening: In the meta-analysis published by the United States Preventive Services Task Force (USPSTF) about screening for osteoporosis [111], it is recommended that re-screening be scheduled according to clinical criteria (low BMI, height loss, etc.) in women with negative initial results, but the USPSTF did not provide an explicit time frame [26]. The optimal interval for re-screening was assessed in 3 guidelines: the Greek guideline [124] and the USPSTF suggested individualized intervals based on "age, and calculated projected time to transition to osteoporosis“ [111] based on the MA cited above [26,111] but they do not recommend a specific time 
frame. The UK guidelines explicitly mention the presence of unmet needs regarding the screening policy [132].

The recently published United States Endocrine Society Clinical Practice Guideline does not recommend any particular time frame for screening [118]; however, it includes two concepts that are crucial hereafter in the BBC 2020 guidelines: "recent fracture" and "imminent fracture risk". A recent fracture is a vertebral or nonvertebral fracture that has occurred within the past 2 years [118]. Among the different timeframes available [161,162], 2 years was generally taken as the timeframe to consider a fracture as recent. The 2-year timeframe for "recent fracture" leads to the emerging concept of “imminent fracture risk". During this 2-year period of time following a fracture, individuals have the highest risk for a new fracture and detection and early treatment might involve the highest benefits. This 2-year time frame helped to categorize the patients as "low risk, high risk, and very high risk" in the new algorithm of the IOF $[134,161]$. Screening by risk factors at least every 2 years might ensure that all patients with incident major clinical risk factors within the 2 years are checked and that no patient at the highest risk of fracture remains undiagnosed and untreated.

In summary, despite the limited evidence, applying a continuous opportunistic screening for clinical risk factors in combination with a new formal screening check every 2 years could be considered.

\section{Q3: WHICH TOOLS should be used to diagnose osteoporosis and assess fracture risk in postmenopausal women?}

Three MA [30,41,52], 9 SR [98,99,101-107], 18 guidelines [1,2,110$114,117,118,120,121,123,124,126-128,132,133]$ and 24 articles from the manual search [138,140,146,148,152-154,159,160,171,182,191,193,195,203,204,213,220-

223,228,233] contained relevant information for this PICO question. Differential diagnosis to exclude secondary causes of osteoporosis or other metabolic bone diseases, multiple myeloma, etc. should be considered [1] before starting management of osteoporosis (Table 4S).

This section has been divided into 3 sub-sections:

Q3.1. Existing tools for the identification of previous fragility fractures, particularly vertebral fractures [1 SR [101], 2 guidelines [1,128], 7 articles by manual search [138,146,159,191,193,195,203]. 
Q3.2. Existing tools for BMD assessment [1 MA [52], 4 SR [98,102,104,106], 13 guidelines [1,110-112,118,120,121,123,124,127,128,132,133], 7 articles by manual search [148,152-154,193,213,233].

Q3.3. Existing fracture risk assessment tools [2 MA [30,41], 4 SR [99,103,105,107], 18 guidelines [1,2,110-114,117,118,120,121,123,124,126128,132,133], and 11 articles from the manual search [140,160,171,182,194,204,220-223,228].

\section{Q3.1. Existing tools for the identification of previous fragility fracture and the} identification of vertebral fracture: The WHO defines fragility fracture as "a fracture that results from mechanical forces that would not ordinarily result in fracture, known as low-level (or 'low energy') trauma, equivalent to a fall from standing height or less [193]". The terms "fragility fracture" and "osteoporotic fracture" are used interchangeably. Vertebral, pelvis, hip, femur, humerus, and forearm (which includes proximal and distal radius/ulna, and wrist fractures -depending on subject's age-) are considered major osteoporotic fractures (MOFs). Rib, tibia/fibula and/or ankle fractures, for example, can also be osteoporotic fractures and qualify as "previous fractures” for use in fracture risk assessment tools, but they are not MOFs [159]. This definition of MOF is slightly different than that in the FRAX model, which considers vertebral, forearm, hip and shoulder fracture. The number and severity of vertebral fractures is also important, since a higher number or severity of vertebral fractures portends a greater risk of new additional vertebral fractures [203]. However, it should be acknowledged that the risk of subsequent fracture could be age-dependent according to the site of the first fracture.

For example, forearm fracture, carry a lower imminent fracture risk in younger than in older postmenopausal women [159]. Considering every woman $\geq 50$ years with a forearm fracture as "very high risk" is probably incorrect, but the risk of imminent fractures is even higher after an index fracture of the forearm than after an index hip fractures in those aged 75 years and older. Therefore, persons aged $\geq 75$ years with a previous recent forearm fracture should be considered at very high risk, but this is not correct for younger persons, as their imminent risk after an index forearm fracture is lower [159]. These elements should be taken into account in the assessment of the severity of osteoporosis, as there are several definitions of MOF, the terminology has not been unified yet, and it varies among different publications. 
$\mathrm{X}$-ray radiography is the recommended imaging technique to confirm a fracture. More particularly, for fractures of the lumbar and thoracic spine, lateral spine radiography is considered the gold standard imaging technique to identify vertebral fracture [101]. An alternative method called vertebral fracture assessment (VFA) by DXA devices is also available [101,146]. The VFA quality imaging is lower, and the interpretation may be challenging, e.g., for higher dorsal vertebrae or in severe osteoporosis. Compared to Xray spinal radiography (vertebral fracture Genant grade $\geq 2$ ), VFA presented moderate sensitivity 0.84 (95\% CI, 0.72- 0.92) and high specificity 0.90 (95\% CI, 0.84-0.94) in a MA. These results were considered insufficient by the authors of that MA to support the use of VFA instead of X-ray for the identification of vertebral fractures in daily practice $[101,146]$. Advantages of VFA include a radiation dose less than $1 \%$ of that from a comparable radiograph and a lower cost. According to the point-of-care principle, VFA can be performed simultaneously with DXA and thus increase the identification of vertebral fractures [195]. Its use to study the presence of vertebral fractures in the presence of a determined age, height loss, and treatment with glucocorticoids has been recommended by the International Society for Clinical Densitometry [191]. VFA is among the recommendations of the Working Group of the Royal Belgian Society of Rheumatology [138]. Based on its low radiation dose and cost-effectiveness, the use of VFA in patients with low clinical suspicion of vertebral fractures could be considered.

Q3.2. Existing tools for the assessment of bone mass: BMD measured by DXA has been the international gold standard to diagnose osteoporosis since 1994. Three simultaneous sites of the body are recommended: lumbar spine (L1-L4), femoral neck, and total hip [1,193]. BMD is a strong predictor of fractures, and each SD below normal values approximately doubles the risk of fractures [152]. None of the different MA and SR identified in our search had a primary objective to assess the validity of DXA $[52,98,102,104,106]$, but they used DXA to measure the diagnostic accuracy of other methods. The different guidelines that include diagnosis among their sections recommended DXA as the method of choice for measurements of BMD $[1,111,118]$. Note that while access to DXA is limited in some countries, Belgium has an exceptionally high number of bone densitometers per capita [1], but reimbursement criteria may limit its use. 
A MA that assessed ultrasound as a tool to assess bone strength showed that it correlated with risk of fracture [52] and could estimate site-specific BMD from specific parameters (speed of sound and broadband ultrasound attenuation). However, only site-matched comparisons have acceptable correlation, while the correlation of peripheral ultrasound assessment with central DXA is low. The 3 SR pointed out that reference values in the target populations were needed before considering ultrasound as an alternative to DXA to estimate fracture risk in clinical practice. Moreover, quantitative ultrasound would be difficult to use in the diagnosis of osteoporosis as its values substantially overlap in young and older individuals, and in fact, the only recognized role of this technique for the moment is to identify individuals who do not require a DXA assessment [102,104,106].

A SR about the opportunistic use of computed tomography (CT) imaging to measure BMD was found, but the differences between devices available, the elevated radiation exposure compared to DXA, and the lack of standardized procedures limit its applicability [98]. None of the 13 guidelines included ultrasound or CT imaging among their recommendations.

Trabecular bone score (TBS) is a texture-based analysis algorithm that can be applied to spinal DXA images and used to adjust fracture risk estimations by FRAX ${ }^{\circledR}$ [213], as shown by one MA [153]. In the current version of TBS, the BMI is used as a surrogate of the soft tissue thickness in a range of BMI, but outside that range, the image does not deliver accurate TBS values. The next version of the software is expected to gain knowledge about the soft tissue thickness data to correct TBS values without using BMI, and is a work in progress [148]. Recent updates of the proprietary software have further refined TBS, and the European guidance includes TBS in its recommendations. Emerging tools include central and peripheral (high-resolution) quantitative CT, nanoindentation, and radiofrequency echographic multi spectrometry (REMS), a nonionizing axial skeleton technology for osteoporosis diagnosis and fracture risk assessment [233]; however, these are currently either unavailable or available only on a research basis in Belgium.

Q3.3. Existing fracture risk assessment tools: For the 48 different fracture risk assessment tools identified through one recent SR [99], the authors found an overall satisfactory performance for most of them. However, methodological limitations were 
found, and only three of them [i.e., the Fracture Risk Assessment Tool (FRAX ${ }^{\circledR}$ ) [220], Garvan fracture risk calculator [221,222], and Q-fracture [223]] appear to be externally validated in cohorts different than those in which they were developed. The three tools largely differ in terms of the risk factors that are considered, e.g., falls are considered in Garvan and Q-fracture. Furthermore, in Garvan and Q-fracture, some of the risk factors are also quantified, e.g., number of fractures, number of falls, units of alcohol intake, etc. The Garvan fracture risk calculator calculates 5-year and 10-year risks of hip fracture and any (not only “major”) osteoporotic fracture. Q-fracture can also give the same outcome (10-year fracture risk, apart from the 1, 2, 3, etc.-year fracture risk) and could be considered; however, it is validated only in the UK and recommended only in the UK and Scottish guidelines [132]. In a clinical guideline, it seems important to propose tools that have the same outcome (i.e., the 10-year risk of fracture). With that in mind, FRAX ${ }^{\circledR}$ and Garvan could be considered in Belgium. However, FRAX ${ }^{\circledR}$ has the largest number of independent and externally validated studies [30]. FRAX ${ }^{\circledR}$ can identify individuals at higher risk of fracture as long as the tool is calibrated for its country-specific use [41]. FRAX ${ }^{\circledR}$ can be used with or without BMD, but a systematic review found that $\mathrm{FRAX}{ }^{\circledR}$ with $\mathrm{BMD}$ can identify individuals at higher risk for fractures better than FRAX ${ }^{\circledR}$ alone $[41,103]$. The use of FRAX ${ }^{\circledR}$ and DXA together was also supported by the findings from the SCOOP [160], SOS [171], and ROSE [182] studies. The FRAX ${ }^{\circledR}$ calibrated for Belgium is available [204,228], and Belgium is the country with the most FRAX ${ }^{\circledR}$ calculations in the world (because it is required for reimbursement for DXA). In Europe, the European guidance [1], the National Osteoporosis Guideline Group (NOGG) and the IOF [103] recommend the use of FRAX ${ }^{\circledR}$ and DXA together. Among the 18 guidelines that include a section about assessment tools, all of them incorporate FRAX® and DXA among their recommendations.

\section{Q4. WHICH THRESHOLDS should be used to diagnose and assess the severity of osteoporosis in postmenopausal women?}

Three MA [30,41,52], 6 SR [99,102-106], 14 guidelines [1,110$112,115,118,120,121,123,124,127,128,132,133]$, and 22 articles by manual search [139,140,145,147,155-163,166,195,199-201,204,215,224,228] contained relevant information for this PICO question. This section has been divided into the same 3 sub- 
sections considered for "WHICH TOOLS" to provide the corresponding thresholds for each tool.

Q4.1. Identification of fragility fracture [3 guidelines [1,118,126], 6 articles by manual search [161,162,195,199,215,224]].

Q4.2. BMD [2 MA [30,52], 6 SR [99,102-106], 14 guidelines [1,110$112,115,118,120,121,123,124,127,128,132,133]$, and 5 articles by manual search [155-158,166]]

Q4.3. Fracture risk assessment tools and studies about their thresholds [2 MA $[30,41], \quad 4 \quad \mathrm{SR} \quad[99,103,105,107], \quad 14$ guidelines $\quad[1,110$ $112,115,118,120,121,123,124,127,128,132,133]$, and 11 articles by manual search [139,140,145,147,159,160,163,200,201,204,228]

Q4.1. Identification of fragility fracture: A vertebral fracture is defined as at least a $20 \%$ reduction in vertebral height (SQ1: $20-25 \%$ ) on X-ray spinal radiography using the Genant semi-quantitative method, which already confers a 2.5-fold greater risk of subsequent vertebral fractures [224]. More severe grades (SQ2: 25-40\%; SQ3: >40\%) incur an even greater fracture risk [224]. The semi-quantitative method is considered the gold standard for identifying vertebral fractures by the IOF and the European Society of Clinical Radiology [215]. Other methods for radiological assessment of vertebral fracture have been studied, e.g., the quantitative morphometry assisted by Spine Analyzer ${ }^{\circledR}$ (QM SA) method, which evaluates vertebral height loss and the algorithmbased qualitative (ABQ) method, based on endplate integrity [195,199]. VFA could also be considered in patients with low suspicion of vertebral fracture [191].

Q4.2. BMD: Based on our literature search, the threshold considered in the majority of references is a BMD (assessed by DXA) of at least 2.5 SDs (i.e., T score $\leq-2.5$ ) below the reference population, which are young healthy U.S. women 20-30 years old in the NHANES reference population. NHANES database was available for proximal femur BMD only, and even a different version for femoral neck and total hip. For lumbar spine, other databases were used [193]. Out of 18 national guidelines examined, 14 included a T-score $\leq-2.5$ threshold for BMD. BMD is a continuous variable, where a lower T-score indicates higher risk. Some authors have pointed out that a T-score $\leq-3.5$ could be considered "very high risk" [166] and is used as a reference in this guideline. Therefore, patients with a T-score $\leq-3.5$ should be considered at "very high risk". 
Moreover, a low BMD $\leq-3.5$ would lead the diagnostic workout to the exclusion of secondary osteoporosis.

Regarding osteopenia, the European guidance states that "low bone mass (osteopenia) should not be considered a disease category” [1]. However, a recent randomized controlled trial by Reid et al. showed for the first time that antiresorptive treatment can also reduce the risk of fracture in osteopenic postmenopausal women [155]. This reinforces the concept that an osteopenic BMD T-score should not disqualify an individual for the diagnosis of osteoporosis, fracture risk reduction strategies, or pharmacological treatment of osteoporosis in patients with an otherwise increased risk. Since it may be confusing to dissociate an intervention threshold from a diagnostic threshold, the U.S. National Bone Health Alliance has recommended to diagnose osteoporosis in patients with an increased fracture risk based on clinical risk factors [163]. Indeed, it is well known that DXA has great specificity (when other metabolic bone diseases have been excluded) but low sensitivity, since the majority of osteoporotic fractures occur in patients with a T-score >-2.5 [156-158].

\section{Q4.3. Fracture risk assessment tools and studies about their thresholds:}

Fracture risk assessment tools need thresholds to provide guidance about the interpretation of the tool for decision making and target pharmacological interventions, i.e., intervention thresholds, which should be calculated for each country individually [41,103]. According to a SR [103], 120 guidelines used FRAX ${ }^{\circledR}$ worldwide, of which 38 did not provide intervention thresholds. There are no randomized trials specifically designed to validate FRAX ${ }^{\circledR}$ thresholds. However, the recent SCOOP trial found significant reductions in hip fracture risk based on a treatment strategy involving population-based screening using the UK FRAX ${ }^{\circledR}$ model [160]. Moreover, the SCOOP trial found that a systematic screening using the FRAX ${ }^{\circledR}$ score led to an increased use of, and adherence to, anti-osteoporosis medications [139].

Belgian country-specific fracture risk assessment tools are available [204,228], and thresholds should be proposed to provide guidance about their interpretation to target pharmacological interventions in a more efficient way.

When using fracture risk assessment tools, three approaches are possible: fixed, agedependent, and hybrid thresholds. According to the first model, treatment is indicated when the 10-year fracture risk of an individual exceeds the 10-year fracture risk at 
which treatment becomes cost-effective. According to the second model, treatment should be considered when the 10-year probability for a MOF or a hip fracture in the patient is higher than that of a person with a prior fracture, no other clinical risk factors and a BMI of $25 \mathrm{~kg} / \mathrm{m}^{2}$ (“fracture threshold”). The third model incorporates a fixed threshold after a certain age that was developed to avoid any discrimination based solely on chronological age [1,132]. The updated UK NOGG guidelines incorporate such a hybrid model, with a threshold that increases with age until the age of 70 years and a fixed threshold for patients aged 70 and older, i.e., $>20 \%$ for MOF and $>5.4 \%$ for hip fractures [132]. In contrast, the NOF of the US proposes a fixed threshold of $20 \%$ for MOF and 3\% for hip fracture, based on cost-effectiveness models [128]. Although these thresholds should be calculated for each country individually, the NOF thresholds are the most commonly used thresholds in Europe [103].

Despite the absence of strong evidence, we propose a model with a fixed threshold of MOF $\geq 20 \%$ and hip fracture $\geq 3 \%$ for individuals aged $<70$ and a fixed threshold of MOF $\geq 20 \%$ and hip fracture $\geq 5 \%$ for individuals aged $\geq 70$ (Figure 2 ). These proposed thresholds are a guide for clinical use, suitable for adaptation based on clinical criteria and the individual factors of each patient. As the evidence about these thresholds is very limited, they should be considered as a consensus-based suggestion.

In summary, the BBC 2020 guidelines incorporate an algorithm that includes major osteoporotic fracture, DXA BMD, and fracture risk assessment tools. Patients with a recent major osteoporotic fracture (vertebral, hip, pelvis, femur, humerus, and forearm, which includes proximal and distal radius/ulna and wrist fractures -depending on subject's age-) were considered at very high risk of fracture [159,195,200,201]. DXA BMD T-scores and fracture risk assessment tools are proposed to categorize patients as low risk and high risk.

\section{Q5. WHICH NON-PHARMACOLOGICAL TREATMENT should be recommended in postmenopausal women, according to their risk of fracture?}

This question was previously addressed in the BBC consensus on the nonpharmacological management of osteoporosis [114]. In that consensus document, individualized exercise, muscle strengthening, and balance training to reduce the number of falls and fall-related injuries were encouraged. Calcium and vitamin D, a 
healthy balanced diet rich in dairy products, smoking cessation, and avoidance of excessive alcohol consumption were among the recommendations [114].

For this update, 2 NMA [7,8], 18 MA [20-29,31-35,74,85,95,96,125], 1 SR [97], 18 guidelines [1,2,110,114-121,123-125,128-130,132], and 36 articles by manual search [6,141-144,149-151,167-170,176,177,186-190,202,205-

207,211,226,231,232,235,236,238-244] contained relevant information for this PICO question. This section has been divided into 3 sub-sections:

6.1. Patient education [1 SR [97], 2 guidelines [1,118], and 2 articles by manual search [186,187].

6.2. Physical exercise $[10$ MA [20-25,74,85,95,96], 6 guidelines $[1,114,118,121,128,132]$, and 14 articles by manual search [6,143,144,167170,176,177,205-207,211,226]6.3. Calcium and vitamin D [13 MA [7,8,18,23,27-29,31-35,125], of which 2 were NMA [7,8], 16 guidelines [1,2,110,115,116,118-121,123-125,128-130,132], and 15 articles by manual search [188-190,202,231,232,235,236,238-244].

5.1. Patient education: Two SR found that the most important themes for patient education in osteoporosis are threefold: knowledge of the disease, medication, and diet and exercise [186,187]. The positive effects of education on patients' understanding of their own health status and on outcomes such as pain have been shown. Patient education could modify patients' values and preferences, as identified in a systematic review, as they are influenced by patients' knowledge about the disease [97]. The European guidance, among others, recommends patient education to encourage making healthy lifestyle decisions, to improve adherence to pharmacological treatment, to raise self-awareness about the disease and to become involved in self-care management $[1,118]$.

5.2. Physical exercise: Three major outcomes had an important impact on the quality of life of the patients or on their risk of fracture: the effects of physical exercise on fracture, BMD, and physical function, activities of daily living, and falls. Physical exercise is well known to exert myriad health benefits beyond these aspects and is therefore generally recommended as part of a healthy lifestyle.

Effects on fracture: Strength and resistance training was the most effective type of exercise to decrease the incidence of fracture, but RCTs with fractures as the primary 
endpoint are scarce. A meta-analysis highlighted the inverse association between increasing levels of leisure time physical activity and the risk of hip fracture [85]; another 3 MA that investigated the positive effect of exercise on fractures were found [167-169]. Regarding safety, there is no evidence to suggest that patients with osteoporosis should avoid exercise to reduce their risk of falls and/or fractures, and the meta-analysis showed that physical exercise is related to a reduction in hip fractures [169]. Therefore, with the exception of abrupt, excessive loading [211], physical exercise should be considered safe.

In patients with fractures, physiotherapy and rehabilitation should be considered. The European guidance [1] recommends "regular weight-bearing exercise, tailored to the needs and abilities of the individual patient”, and in patients with advanced stages of osteoporosis, it recommends "multicomponent group and home-based exercise programs for prevention and physiotherapy and rehabilitation after fracture”.

Effects on BMD: Seven MA [20-25,95,96] considered strength/resistance training as the most effective type of exercise for postmenopausal women with osteoporosis [20,23,96]. Moreover, exercises, mainly land-based (also called “ground-based”) strength/resistance exercises, can increase BMD at the femoral neck and lumbar spine, but the exact modalities are not well defined [20-22,24]. The effect of exercise on BMD largely depends on the intensity of the exercise: for impact training to have an effect on BMD, the intensity of the impact should be equal to a gait speed $>6.14 \mathrm{~km} / \mathrm{h}(1.7 \mathrm{~m} / \mathrm{s})$ [176]. However, with increasing age, the focus of exercise should be modified progressively from bone loading to muscle loading to improve coordination and muscle strength. Likewise, progressive resistance training is only effective when targeted at the muscles attached to or near to the spine and hip, and loads $<80 \%$ of the 1 maximum repetition (maximum weight that an individual can lift; it is given as a percentage of the desired load and adapted to the individual characteristics) are generally ineffective [177]. Impact training and a combination of resistance training and weight bearing in postmenopausal women should be considered [95,205].

Effects on physical function, activities of daily living, and falls: Multicomponent intervention exercises had the greatest beneficial effects on functional status in individuals with osteoporosis [74]. Multicomponent and exercise interventions may be helpful to mitigate fall-related outcomes (including fall-related injuries and fear of 
falling) in community-dwelling [170,206] and institutionalized [207] older patients by adapting the intervention to the characteristics of these two populations. Postmenopausal women at risk for fractures should be screened for fall risk by asking about the number of previous falls, particularly in the past year, administering the 30second Chair stand test [143], assessing visual or hearing loss, polypharmacy ( $\geq 4$ medications, e.g., benzodiazepines, antidepressants, blood pressure lowering drugs, etc.), by reviewing of environmental hazards, and by observing gait and mobility. Patients with $\geq 1$ fall/year or one injurious fall should be offered multicomponent (targeting individualized extrinsic and intrinsic fall risk factors) and/or exercise interventions, including balance training. Individualized, tailored interventions are recommended by the European Union Geriatric Medicine Society [226] and the USPSTF [170], among others.

Physical activity regimens: Some practical advices, including diagrams and illustrations are available in the Too Fit to Fracture consensus [144] and on the IOF website (https://www.iofbonehealth.org/exercise).

\subsection{Calcium and vitamin $D$.}

Efficacy: The most recent NMA meta-analysis available in our search, by Barrionuevo et al., 2019 [7], compared the effective estimates for various interventions to reduce the risk of fracture. This NMA showed that calcium in combination with vitamin D produced a reduction in hip fractures but that the efficacy was considerably lower than the reduction obtained by the anabolic therapy and antiresorptive treatments included in the analysis [7]. The second NMA, published in 2012, concluded that calcium and vitamin $\mathrm{D}$ reduced the risk of hip fracture if they were administered together but not separately [8]. Additive beneficial effects for combined strength/resistance exercise training and vitamin D supplementation on musculoskeletal health were found [23].

Calcium associated with vitamin D has shown efficacy in reducing the risk of hip and other fractures. A daily intake of at least 1,200 mg/day (but not more than 2,000 $\mathrm{mg} /$ day) is recommended in patients at any risk of fracture, and calcium obtained from food intake and dairy products is the preferable source $[119,130]$. If this daily intake is not achieved by food intake, oral supplements should be considered. Excess calcium intake does not incur greater skeletal benefits. Treatment should be tailored to the different clinical situations. For example, higher calcium doses may be required after 
bariatric surgery, in patients with achlorhydria, etc. The possibility of pharmacological interactions (e.g., calcium absorption might be reduced by proton pump inhibitors) should be considered before prescribing calcium supplementation, as the difference in absorption between calcium citrate and calcium carbonate is dependent on gastric $\mathrm{pH}$ [2].

Regarding vitamin $\mathrm{D}$, it is important to note that in patients who receive antiresorptive or anabolic drugs, vitamin D supplementation is recommended. Indeed, most of the clinical trials assessing the effectiveness of these drugs have been performed with the concomitant use of vitamin $\mathrm{D}$, independent of baseline vitamin $\mathrm{D}$ status to avoid incident vitamin D deficiency and reduce the risk of hypocalcemia. However, in patients with a low risk of fracture for whom no pharmacological treatment is considered, if the target 25-hydroxyvitamin D (25OHD) levels are achieved (see below), those patients might not need vitamin D supplementation.

The evidence found does not justify the screening for vitamin $\mathrm{D}$ in the general postmenopausal population, but does in those postmenopausal women with at least one major risk factor, and who therefore should undergo further assessment of osteoporosis. The systematic measurement of serum levels of vitamin D is not recommended in most guidelines, which rather propose a systematic supplementation with vitamin $\mathrm{D}$ in all osteoporotic patients. The recommendation to systematically assess vitamin D status in all postmenopausal women with at least one major risk factor who, therefore, underwent osteoporosis assessment was a suggestion of the BBC guidelines development group, to avoid supplementation of vitamin D in women with normal serum vitamin D levels, who are at low risk of fractures and do not receive any pharmacological treatment. Such a systematic assessment also allows to check compliance.

Blood levels of 25-hydroxyvitamin D should be measured for the systematic determination of vitamin $\mathrm{D}$ status by an accurate and standardized method before starting pharmacological treatment, to help in the monitoring of its levels and to assess compliance with treatment. Laboratories measuring serum 25OHD should participate in quality controls, i.e. Vitamin D External Quality Assessment Scheme (DECAS) and report percentage of bias versus the National Institute of Standards and Technology (NIST) standards. Several recommendations about the target levels of vitamin D are 
available [188-190]; however, most guidelines agree that the minimal 25hydroxyvitamin D threshold should be $\geq 20 \mathrm{ng} / \mathrm{mL}$ (50 nmol/L), and that levels $\geq 50$ $\mathrm{ng} / \mathrm{mL}(125 \mathrm{nmol} / \mathrm{L})$ could be considered deleterious. In the Calgary trial, with 4,000UI, the levels that were reached of $132-144 \mathrm{nmol} / \mathrm{L}$ were already associated with a BMD decline [238], so, the suggested $\leq 50 \mathrm{ng} / \mathrm{ml}$ i.e. $125 \mathrm{nmol} / \mathrm{L}$ might be indeed appropriate as a superior target level. A daily dose of $800-1,000$ IU should be considered, and the dose could be adapted according to the clinical status of the patient and the monitoring results. In subjects receiving a pharmacological treatment, a dose of vitamin D of 800 IU-1,000 IU per day or its equivalent on a weekly or monthly basis with a monitoring of the 25OHD level was recommended in most of guidelines. These recommendations are also part of the ESCEO recommendations for calcium and vitamin D [116].

Healthy, balanced diet rich in dairy products, should be considered. Several studies reported benefits of Mediterranean diet in all health outcomes [241,242], and a higher adherence to Mediterranean diet has been showed to be related to a reduction in the risk of hip fracture (RR 0.95, 95\% CI 0.92-0.98 $p=0.01$ ) and a higher BMD [244]. An intake of up to three servings of dairy products per day has been shown to have benefits for bone health and has been considered as safe [243]. Individuals who follow calorie restriction, intermittent fasting, vegetarian, or vegan diets should consider dietary sources of calcium and vitamin D and/or supplementation [235,236].

Safety: A MA from the USPSTF and one from Cochrane found an association between calcium and vitamin D and the risk of kidney stones compared with placebo (absolute risk difference $0.33 \%$ [95\% CI, $0.06 \%$ to $0.60 \%$ ]), without any other risks associated [18]. Other studies [195] and MA support a possible risk of hypercalciuria and renal stones with high vitamin D doses. Large, spaced vitamin D doses (e.g., 250,0001,000,000 IU every 3-12 months) led to a higher risk of falls and fractures in older patients and should not be administered. Daily doses of vitamin $\mathrm{D} \geq 3000$ IU should be avoided [238]. The effect on vascular calcification and coronary heart disease remains somewhat controversial, but the risk is not clinically relevant; calcium with or without vitamin $\mathrm{D}$ does not increase coronary heart disease or all-cause mortality risk $[31,34,125,129]$.

Outside calcium and vitamin $\mathrm{D}$, several nutrients and type of diets have been shown to have a more direct impact on bone health. 
Proteins: Long-term, high-protein intake has been shown to have positive effects in BMD and reduced risk fracture in epidemiological, observational studies. In the short term, interventional studies that included high-protein intake, have been shown to have beneficial effects in bone health [141]. The recommended daily allowance (RDA) dose of proteins in general, healthy populations is $0.8 \mathrm{~g} / \mathrm{kg} /$ body weight/day. The systematic review and position paper from the PROT-age group concluded that a protein intake of 1.0 to 1.2 $\mathrm{g} / \mathrm{kg} /$ body weight/day obtained the greatest benefits in BMD in patients $\geq 65$ year-old with osteoporosis and in patients with all types of fracture [149]. This recommendation has been endorsed by the ESCEO and the EuGMS [150]. The major dietary sources of proteins are provided from animal sources, i.e., red meat, poultry, viscera, fish, seafood, eggs, dairy products (cheese, yoghurt and similar, and milk), and they are also present in vegetable sources, i.e., legumes (chickpeas, beans), soy-derived products (tofu), nuts, and seeds [151].

Different type of diets: A recent meta-analysis of cohort, case-control, and crosssectional studies assessed the effect of dietary patterns and diets in bone health, defined by a lower BMD and risk of fracture. Diets defined as « unhealthy », "Western », or «processed» composed by «hamburgers and fried foods, pickles, snacks, cola beverages, coffee, and sugar », were compared with diets defined as "Healthy ", « Health conscious », " Prudent », " Dairy and fish », " Milk and root vegetables » or «Fruit, milk, and whole grains”, composed by «fish, low-fat milk, dairy products, legumes, vegetables, fruits, whole grains, nuts, and olive oil ». The second pattern had a protective effect on bone health and decreased the risk of having a low BMD in all ages. Moreover, individuals following the second « Healthy » pattern showed a lower risk of fracture [142].

In summary, adherence to Mediterranean diet, poor in saturated fats, rich in fish, vegetables, fruits, nuts, and olive oil [241,242]; diets rich in calcium, diets rich in dairy products, including up to three servings of dairy products per day might be considered [114]. Individuals following special diets should be checked up and supplemented on a tailored, individual basis [151,235,236].

Q6. WHICH PHARMACOLOGICAL TREATMENT should be recommended in postmenopausal women with osteoporosis, according to their risk of fracture? 
Eleven NMA [7-17], 55 MA [36-40,42-51,53-62,64-73,75-84,86-94], 15 guidelines [1,2,109,110,115,117,118,120-124,128,131,132], and 11 articles by manual search [136,172,208,209,216,217,225,227,234,245,246] contained relevant information for this PICO question.

Five different types of pharmacological treatments were found: 1) menopausal hormone therapy, 2) SERM (raloxifene and bazedoxifene), 3) bisphosphonates, 4) denosumab, and 5) anabolic therapy (teriparatide, abaloparatide, and romosozumab). Strontium ranelate is no longer available.

Efficacy: All five different types of pharmacological treatments were found to be effective for fracture risk reduction. The most recent NMA available in our search, by Barrionuevo et al., 2019 [7], included most of these treatments and found that they were effective for preventing hip fracture or vertebral fractures. The highest relative fracture risk reduction was obtained by anabolic therapy (romosozumab, abaloparatide, or teriparatide) for hip and vertebral fracture. Antiresorptive treatment (most bisphosphonates, denosumab, and SERM) resulted in a moderate risk reduction in vertebral, nonvertebral and hip fractures. SERM (raloxifene and bazedoxifene) had lower efficacy than bisphosphonates or denosumab in vertebral fractures and have not been shown to prevent nonvertebral or hip fractures; note that menopausal hormone therapy was not included in this NMA. The risk reduction of menopausal hormone therapy (estrogen with or without progesterone) probably depends on the molecule and dosage used and ranges between SERM and calcium with vitamin D [7].

In the NMA by Reginster et al., 2019, all treatments showed efficacy for the reduction of vertebral fractures against a placebo, but in the head-to-head comparison, anabolic therapy with abaloparatide, romosozumab, and teriparatide showed the highest efficacy, bisphosphonates and denosumab showed intermediate efficacy, and SERM showed the lowest efficacy among the drugs included and did not reduce hip fracture [10]. Similar results were obtained in the NMA by Yang et al. 2019 [11]. In the recent NMA by Hernández et al., abaloparatide, romosozumab, and teriparatide obtained the highest efficacy in reducing vertebral and nonvertebral fractures [172].

All bisphosphonates (alendronate, ibandronate, risedronate, and zoledronate) showed efficacy in reducing vertebral fracture compared with a placebo in the NMA by Zhou et al. 2016 [9] and in reducing vertebral fracture and hip fracture, though the effect on the latter was small, in Sanderson et al., 2016 [17] and Jansen et al., 2011 [15]. Zoledronate 
was shown to be associated with a higher reduction in hip and vertebral fracture than the three oral bisphosphonates [15,17]. In contrast to other available bisphosphonates, ibandronate has not demonstrated efficacy against nonvertebral fractures in RCTs although the study was not designed for that objective [15,17].

Combination therapy has been shown to increase BMD more than its individual components but no trials have been adequately powered for fracture outcomes, and guidelines do not recommend it due to its higher costs without proven anti-fracture benefits [118]. Sequential treatment of antiresorptive therapy after anabolic treatment [245] and bisphosphonate after denosumab discontinuation [1,118] should be recommended because beneficial anti-fracture and BMD effect of anabolic therapy and denosumab are reversible and quickly disappear after the treatment is stopped. In case of denosumab discontinuation, treatment with bisphosphonates should be recommended, in order to avoid the occurrence of multiple vertebral fractures, but specific guidelines on the optimal bisphosphonate treatment schedule are not available yet. In those cases where antiresorptive treatment is replaced by anabolic therapy, monitoring is recommended [225,227]. New therapies such as local osteo-enhancement procedures (LOEP) [134,234] are still not available in clinical practice in Belgium.

Safety: Safety issues were found for teriparatide and abaloparatide (tachycardia and palpitations, hypercalcemia), romosozumab (increased risk of cardiovascular adverse events, hypocalcemia, and osteonecrosis of the jaw), bisphosphonates (hypocalcemia, atypical femoral fractures and osteonecrosis of the jaw, atrial fibrillation in one study with zoledronate, and nephrotoxicity in case of fast infusion with zoledronate), denosumab (hypocalcemia, atypical fractures and osteonecrosis of the jaw, rapid loss of bone and vertebral fractures after discontinuation), SERM (increased risk of thromboembolic disease and vasomotor symptoms, and leg cramps), and menopausal hormone therapy (increased risk of breast cancer, stroke, and thromboembolic diseases). A reduced risk of hormone-sensitive breast cancer has been observed with raloxifene [246]. The side effects of menopausal hormone therapy may depend on the molecule used, the route of administration, and the age at the start of therapy $[1,118,132]$. Additional information about romosozumab was found on the EMA website, stating that the Marketing Authorization report pointed out that romosozumab was associated with higher pooled risk of death in patients aged 75 and above. This higher risk of mortality 
of romosozumab in patients $\geq 75$-year-old should be taken into account in the selection of the three different anabolic agents available.

In summary, anabolic drugs were more potent than antiresorptive treatment to reduce the risk of fracture and to increase BMD quickly, and could thus be preferred for patients at very high risk, followed by antiresorptive therapy. Antiresorptive treatment (bisphosphonates and denosumab) should be considered in patients at high risk $[208,209]$. SERM may be considered in postmenopausal women $\leq 65$ years of age with vertebral osteoporosis without an increased risk of hip fracture and without contraindications to SERM (i.e., non-smokers with no cardiovascular history), in women additionally seeking for breast cancer prevention or in patients with contraindications to other treatment options. Menopausal hormone therapy is the treatment of choice for climacteric symptoms; at a sufficiently high dose, it has shown bone protection effects. It should be considered in women (in the range of 50-60 years of age) for the treatment of climacteric symptoms; at a sufficient dose for bone protection, favouring low dose estrogens (starting from estradiol $0.25 \mathrm{mg}$ oral) and safe progestins, or in patients where other options are contraindicated.

\section{Q7: HOW should the treatment of osteoporosis be monitored in postmenopausal women?}

One MA [63], 14 guidelines [1,109,110,113,118,120-124,126-128,131], and 14 articles by manual search [164,165,173-175,196,212,215,218,219,229,237,247] contained relevant information for this PICO question. Because of the lack of unified goals of treatments in the existing guidelines, the goals of treatment ("a successful treatment in osteoporosis”) were defined according to the European guidance [1]: no incidence of new fragility fractures, stable or increasing BMD, and achieving the reference target for BTM, which is the least significant change showing treatment efficacy [173-175]. Some authors also considered achieving a BMD T-score $\geq-2.5$ to $>-2.0$ as the target ("treat-to-target” concept) [175]. Conversely, treatment failure can be considered "when two or more incident fragility fractures have occurred after $>1$ year of treatment, when serial measurements of bone remodelling markers are not suppressed by antiresorptive therapy and when BMD continues to decrease” [165]. In these scenarios, possible underlying causes should be identified, e.g., compliance issues, incorrect drug use, calcium and/or vitamin D deficiency, or incident or undetected secondary causes of 
osteoporosis. Monitoring should be focused on compliance, as a lower compliance has been associated to an increased fracture risk [1].

This section has been divided into 3 sub-sections:

Q7.1. Identification of new fragility fractures [2 guidelines [1,118] , 1 article by manual search [215]].

Q7.2. Monitoring of treatment with BMD measured by DXA [3 guidelines $[1,118,128]$ and 3 articles by manual search [164,196,229]].

Q7.3. Monitoring of treatment with BTM [1 MA [63], 1 SR [100], 4 guidelines

[1,63,118,131], and 8 articles by manual search [173-175,212,218,219,237,247].

\subsection{Identification of new fragility fractures and identification of new vertebral} fractures during monitoring: For monitoring new fragility fractures, clinical interviews and physical examinations are recommended. Moreover, X-ray spinal radiography [215] might also be performed to detect new vertebral fractures or progression in the severity of pre-existing vertebral fractures if indicated according to clinical criteria (loss of height, back pain, etc.) [1,118]. Some authors considered that VFA might be useful to monitor treatment; however, its use is still in the process of implementation in clinical practice, and it has not been included in the guidelines assessed [1,118].

7.2. Monitoring of treatment with BMD measured by DXA: The European guidance considered an 1-2\% increase per year as an adequate treatment-induced increment in BMD with inhibitors of bone turnover, and this increment, or even higher, can be achieved more rapidly with anabolic agents [1]. BMD does not continuously increase year by year with bisphosphonates, but levelling off is observed after 3-5 years. The American Association of Clinical Endocrinologists [118] and American College of Endocrinology guidelines [128] do not require any improvement in BMD and consider a stable BMD during monitoring an appropriate target. Observational studies suggest that BMD monitoring might be associated with greater compliance, switching to more potent medications (e.g., oral to parenteral route) [229] and a reduced fracture risk [164]. However, no randomized trials have compared different follow-up strategies.

The mean group effects are derived from clinical trials with high quality DXA as a target. For clinical practice in individual patients, one should advice that a DXA device calculates its own precision error and least significant change. The DXA management in 
the overall clinical practice (for which this guideline is written) is not always of optimal quality and one should take into account the error of the individual measurement. So, careful interpretation of individual DXA results should be done in respect to a documented least significant change and individual factors of the patient.

7.3. Monitoring of treatment with BTM: Two BTM, serum procollagen type I Npropeptide (s-PINP), a bone formation marker, and serum C-terminal cross-linking telopeptide of collagen (s-CTX), a bone resorption marker, are related to risk of future fracture and are useful for monitoring according to a meta-analysis [63]. The update of the algorithm for the use of biochemical markers of bone turnover in the assessment and follow-up of treatment for osteoporosis by ESCEO [237] showed that the two BTM decreased rapidly after initiating antiresorptive treatment and that the change in their serum levels is correlated with the gain in BMD [237]. In a study using BTM to monitor response to risedronate, BTM were shown to reinforce postmenopausal women's persistence to treatment, and as result, a decreased occurrence of new vertebral fracture [OR: $0.4(0.2-1.0)]$ was observed [212]. The lack of decrease observed in BTM in patients with antiresorptive treatments can indicate non-adherence to the treatment, issues with drug administration (e.g., decreased absorption of oral bisphosphonates due to incorrect intake with food or calcium supplements), or failure of treatment. A caveat could be that BTM must be measured in the morning and in a fasting state to avoid excessive intraindividual variations. The two BTM, but mostly s-CTX, have been recommended for monitoring adherence with bisphosphonates and denosumab, and PINP has been recommended for monitoring treatment with anabolic drugs in clinical practice [237] by the International Federation of Clinical Chemistry and Laboratory Medicine (IFCC) [63], the European guidance [1], the European Calcified Tissue Society [131], the Guideline of the American Association of Clinical Endocrinologist and the American College of Endocrinology [128], among others. The IOF and the European Calcified Tissue Society Working Group [131] established reference values for the response of BTM to antiresorptive therapy based on the TRIO study $[218,219]$. The International Federation of Clinical Chemistry and Laboratory Medicine (IFCC) have recently proposed intra-individual coefficients of variation for s-CTX and PINP based on data from the European Biological Variation Study (EuBIVAS) allowing the calculation of the Least Significant Changes for these 2 BTM [247]. A decrease $\geq 31 \%$ for s-CTX and $\geq 20 \%$ for PINP for bisphosphonates and denosumab, and an increase 
$\geq 45 \%$ for s-CTX and $\geq 25 \%$ for PINP for anabolic treatment was defined as the least significant change showing treatment efficacy and could be considered as the reference target for these two biomarkers [247].

Q8. WHEN should monitoring of treatment for osteoporosis be performed in postmenopausal women?

One MA [63], 1 SR [100], 14 guidelines [1,109,110,113,115,118,120-124,128,131,132], and 3 articles by manual search [218,219,237] contained relevant information for this PICO question. The 3 sub-sections of this section are similar to those of the "HOW treatment of osteoporosis should be monitored" section.

Q8.1. Identification of new fragility fractures, identification of new vertebral fractures during monitoring [2 guidelines [1,118]].

Q8.2. Monitoring of treatment with BMD measured by DXA [12 guidelines [109,110,115,118,120-124,128,131,132].

Q8.3. Monitoring of treatment with BTM [1 MA [63], 1 SR [100], 5 guidelines [113,118,120,131,132], and 3 articles by manual search [218,219,237].

\subsection{Identification of new fragility fractures and identification of new vertebral} fractures during monitoring. There is no evidence about the timeframe for administering X-ray spinal radiography or VFA for monitoring, therefore, it should be based on clinical interviews and physical examinations, e.g. measured height loss, plus tailored, individualized criteria that ensure the identification of patients at imminent fracture risk $[1,118]$.

8.2. Monitoring of treatment with BMD measured by DXA. The lack of evidence about the periodicity of monitoring with DXA and the heterogeneity of recommendations among the guidelines was pointed out in the Clinical Practice Guideline Update From the American College of Physicians [121]: this guideline and the European guidance recommend monitoring BMD with DXA every 5 years ("in the absence of other clinical imperatives, a 5-year interval may be appropriate” [1]). The UK guidelines recommend 3 to 5 years [132]; the French Guideline recommends every 2 to 3 years [120]; the United States Endocrine Society Clinical Practice Guideline [118], the Portuguese guideline [123], and the Greek guideline [124] recommend every 2 years; and the Update of the Polish guideline recommends monitoring BMD after 12 months of initiating treatment [110]. In summary, there is a lack of unified 
recommendations about the periodicity of monitoring with DXA, ranging from a 12month to a 5-year interval, depending on the guideline assessed. Given the lack of unified recommendations, the assessment of BMD with DXA every 2 to 5 years, depending on the treatment received, could be an option.

8.3. Monitoring of treatment with BTM. The IOF and the ESCEO recommend to use BTM, 3 months (12-13 weeks) after the initiation of the treatment, to assess adherence to oral BP and provide thresholds for this assessment [237]. The value of obtaining a basal determination before the patient starts the treatment, in order to compare the percentage of change after treatment, remains uncertain given the lack of evidence supporting this practice. One option for monitoring BTM could be measuring at baseline and 3 months (12-13 weeks) after the initiation of treatment. If the least significant change is not observed after 3 months, adaptation of treatment, compliance, and control after 6 months should be further investigated.

Q9. What are the indications for CONTINUING, MODIFYING, and STOPPING the pharmacological treatment of osteoporosis in postmenopausal women?

Four MA [63,71,72,94], 3 SR [69,97,108], 14 guidelines [1,2,109,113,115,118,120124,128,131,132], and 12 articles by manual search [135,178181,183,184,197,210,214,225,227] contained relevant information for this PICO question. Decision making should be made based on the nature of the intervention, achievement of treatment goals, and compliance (See PICO 5-7).

9.1. If the goals of treatment are achieved, 3 options should be considered:

Continue: The maximum duration of each pharmacological treatment depends on the nature of the intervention and varies widely. No evidence to guide decisions regarding treatment longer than 10 years was found, as pointed out in a systematic review [108] and in the UK guidelines. However, this certainly does not mean that therapies that are not suitable for drug holidays (ibandronate, denosumab) or only short drug holidays (ibandronate, risedronate) cannot be taken for $>10$ years. A duration of treatment of 3 to 6 years for zoledronate and of 5 to 10 years for alendronate has been considered by the ASBMR [179]. The benefits of the extension of denosumab up to 10 years have been recently reported based on the FREEDOM extension trial, however, there are some new data reporting benefits on fracture risk beyond 10 years [109,122]. However, no 
guidelines on the optimal duration of denosumab therapy were found. Most guidelines recommend tailored, individualized clinical decisions for long-term treatments [1,2,108,109,113,115,118,120-124,128,131,132]. In patients undergoing anabolic treatment (which typically last 1 to 2 years) and those stopping denosumab therapy (if ever), it is recommended to initiate anti-resorptive therapy to maintain bone mass gains (sequential therapy). A repeat course of anabolic therapy may be considered after 1-2 years [210].

Drug holidays: Treatment interruption for a period of time, termed "drug holidays", is mentioned in 3 MA [69,71,72] and the 14 guidelines [1,2,109,113,115,118,120$124,128,131,132]$ retrieved with our search strategy. Patients receiving long-acting antiresorptive therapy (zoledronate or alendronate; but less for risedronate and ibandronate, and not for denosumab) who achieve their goals can interrupt treatment for a period of time (called a "drug holiday") with no increase in fracture risk. This strategy has been shown in the FLEX and HORIZON extension trials for alendronate and zoledronate, respectively [69]. There is no evidence to suggest that drug holidays reduce the risk of very rare adverse events associated with long-term antiresorptive treatment (atypical femoral fractures and osteonecrosis of the jaw). After 5 years of alendronate treatment in postmenopausal women in the FLEX trial, those who continued alendronate had a lower risk of clinical vertebral fractures [181]. Post hoc analyses showed that in women with a femoral neck T-score $\leq-2.5$, continuation for up to 10 years also reduced nonvertebral fracture risk [183]. In the HORIZON extension trials, there was no subgroup that benefited from 9 compared to 6 annual zoledronate infusions, nor was there any difference in BMD or BTM during a 3-year drug holiday after 6 annual infusions [178]. However, discontinuation after 3 annual infusions was associated with an increased incidence of fracture after a 3-year drug holiday [180]. Patients who do not have low hip BMD ( $\leq-2.5)$, incident fractures during treatment or an increased risk of vertebral fractures may be considered candidates for a drug holiday after 3 years of zoledronate or 5 years of alendronate. Otherwise, they may continue for up to 6 or 10 years, respectively [179]. The UK guidelines recommend that patients on drug holidays should be reassessed in 1-3 years by measuring BMD with DXA [132]. However, there is no evidence to support monitoring of BMD or BTM to gauge the timing of restarting antiresorptive during a drug holiday. 
Stop treatment: A patient's change from a high to a low level of risk is the indication to stop the antiresorptive treatment. This could be also possible in case of a change in modifiable risk factors, e.g., stop of corticoid therapy, nicotine, or alcohol abuse. After stopping denosumab, bisphosphonates should be provided [1,118]. A caveat for stopping treatment could be in patients whose BMD changes category after treatment and who still have "treated osteoporosis" and who cannot be assimilated to "normal", as osteoporosis, even treated and adequately managed, is a chronic disease: "treated osteoporosis is still osteoporosis” [184]. The occurrence of adverse events does not necessarily involve stopping osteoporosis treatment but is a reason to reconsider pharmacological therapy individually. In patients (e.g., very old patients), whose life expectancy is expected to be shorter than the time required to benefit from therapy, i.e., generally $\leq 1$ year, withholding osteoporosis treatment may be considered [198].

Discontinuation of denosumab is not recommended, because it conveys the risk of multiple vertebral fractures in a rather short delay. In case discontinuation is necessary, bisphosphonates should be provided [1,118], in order to avoid the rapid loss of BMD after its discontinuation (sequential therapy). There are no guidelines about the optimal duration of denosumab, with reported benefits up to 10 years [109,122], and a lack of data about its benefits afterwards. Thus, the optimal duration of denosumab would be "lifelong” except if it is followed by treatment with another antiresorptive, but there are no definitive answers about when to start with the alternative antiresorptive and how long it should be given. Further research is required to provide a definitive answer about the optimal duration of denosumab.

9.2. If the goals of treatment are not achieved: Several guidelines $[1,109,118,126]$ have assessed the failure to achieve the goals of treatment and indicate the need to reconsider a differential diagnosis with other diseases (i.e., osteomalacia, myeloma), to assess patient adherence to treatment (particularly in patients with oral bisphosphonates) [63], to re-assess patients’ values and preferences [97], and to re-assess risk level (low, high or very high) [165].

Some authors found increases in BMD when switching from bisphosphonates to denosumab, teriparatide [197], or romosozumab [214]. If compliance with or tolerance of oral bisphosphonates is an issue, expert opinion also suggests considering the possibility of switching to denosumab or an intravenous bisphosphonate. Although there 
are no fracture outcomes to support these treatment strategies [165], there is evidence for improved fracture outcomes by increasing compliance/persistence of therapy.

In summary, if the goals of treatment are achieved, three possible options should be considered: continue treatment, take a drug holiday (only applicable for zoledronate and alendronate); and stop treatment (e.g., when contraindications develop). If the goals are not achieved, differential diagnosis with other diseases, adherence to treatment, reassessment of patients' values and preferences, and risk level (low, high or very high) should be considered. However, the BBC board fully acknowledges that the evidence is limited for most of these recommendations and considers this topic a challenge for further research.

\section{STRENGTHS AND LIMITATIONS}

The BBC 2020 guidelines for the management of postmenopausal osteoporosis are comprehensive and include recommendations for screening, diagnosis, treatment, and monitoring (Figure 3). What is new compared to our BBC 2010 guidelines? These guidelines use the most updated evidence-based methodology to propose recommendations. Moreover, consensus-based decisions have been made to provide answers for those topics where the evidence was scarce and did not meet the needs in daily practice. A systematic search to find network meta-analyses, meta-analyses, systematic reviews, guidelines and recommendations from scientific societies published in the last 10 years was conducted, which is an innovative and exhaustive methodology. From the list of 25 recommendations, some of them are particularly specific, practical, and could be very helpful for clinical decision-making: e.g. “ e.g. when to screen for osteoporosis using clinical risk factors, which type of fracture has to be considered as MOF (vertebral, femur, hip, pelvis, humerus, and forearm, which includes proximal and distal radius/ulna, and wrist fractures- depending on subject's age-), the inclusion of the 2-year timeframe for considering a recent $\mathrm{MOF}$, as well as the intervention thresholds proposed.

More specifically, with respect to the intervention thresholds, we have opted for fixed intervention thresholds, according to which treatment is recommended in case of FRAX for MOF $>20 \%$ for all ages and in case of FRAX for hip $>5 \%$ for $\geq 70$ years and $>3 \%$ for $<70$ years. Although FRAX scores can be calculated for Belgian men and women with the FRAX $^{\circledR}$ tool on the website 
(https://www.sheffield.ac.uk/FRAX/tool.aspx?country=18)

and

age-dependent

thresholds for Belgium have been published [204], these thresholds have not been incorporated in the FRAX website, in contrast to the NOGG age-dependent thresholds. As such, the use of these age-dependent Belgian thresholds would imply checking up each patient in the FRAX model graphic after calculating FRAX ${ }^{\circledR}$ on the website for each individual. This is unrealistic to be applied daily, because this process would require extra time for each outpatient visit, a certain level of knowledge and experience and might have limited a wider use. So, this was, partly, a practical issue, as an important aim of the manuscript is providing guidance for prescribing physicians in daily practice.

Apart from being a practical issue, and maybe more importantly, age-dependent thresholds, as proposed by the NOGG for use in the UK [147]_and by Johansson et al for use in Belgium [204], induce inequalities in access to therapy especially at older age, depending on the presence or absence of a prior fracture. For this reason, the NOGG has proposed hybrid intervention thresholds, according to which the intervention threshold increases up to 70 years of age and then remains stable [103][147]. Therefore, we decided not to use age-dependent intervention thresholds.

The rationale for the specific intervention thresholds for hip fracture that we proposed ( $<3 \%$ for 70 years and $<5 \%$ for $\geq 70$ years) is as follows:

First, 3\% for $<70$ years thresholds are based on the fixed intervention threshold proposed by the National Osteoporosis Foundation (NOF). Although we acknowledge that this specific intervention threshold is only valid in the USA and should be calculated for each individual country based on epidemiology of fracture risk, health care budget, health economic considerations, practice guidelines and reimbursement criteria, several national osteoporosis guidelines also include these cut-offs proposed by NOF [103].

Second, $5 \%$ for $\geq 70$ years is based on the fixed intervention threshold proposed by the NOF; indeed, according to the NOF, the 10-year hip fracture probability ranges from $2.5 \%$ at the age of 50 to $4.7 \%$ at 75 years in women and from $2.4 \%$ at 50 years to $4.9 \%$ at 75 years in men. Thus, also the fixed intervention threshold slightly increases at older age, which can be explained by the increased competing mortality risks from other disorders at higher age [145]. In addition, according to hybrid intervention 
threshold model, the threshold remains constant from the age of 70, being at $5.4 \%$ for a hip fracture [103][147]. So, the $5 \%$ for $\geq 70$ years is based on the combined evidence from the NOF fixed threshold and the hybrid threshold.

So, we would like to point out that this decision was based (partly) for the sake of practicability. First, an important aim of the manuscript is to be a helpful guidance for prescribing physicians in daily practice. Providing a guideline that would have required for each patient to first calculate a score with the FRAX tool on the FRAX website and then to check this score unto the FRAX model graphic was unrealistic in daily practice. Indeed, because this process would have required extra time for each outpatient visit as well as a certain level of knowledge and experience and it might have limited a wider use. Furthermore, as mentioned above, the Belgian age-dependent thresholds have not been incorporated in the FRAX tool on the FRAX website, as it has been done for the NOGG age-dependent thresholds

Some limitations and strengths should be highlighted. First, the high-quality methodology we used is a strength of these guidelines. We performed a systematic literature search that included NMA, MA, SR, guidelines, and expert opinions. NMA are a relatively new type of statistical analysis based on the assessment of the relative efficacy of all comparisons independently, in the lack of direct interventions of a lot of direct head-to-head trials. They confirm the findings of two direct head-to head fracture outcome studies between antiresorptive and anabolic therapies, as the VERO [216] (risedronate vs. teriparatide) and ARCH [217] (alendronate vs. romosozumab) trials. NMA have been shown to provide the highest level of evidence in clinical epidemiology [3]. However, this methodology involved a limitation, as we might have missed two types of studies: those published after conducting the literature search and those individual studies that might have not been included in any of the SR or MA. These two potential sources of bias were counteracted by allowing members to suggest relevant publications in the manual search. Unfortunately, evidence remains scarce in many important areas of osteoporosis care, so most recommendations had to be based on moderate- to low-quality evidence. Second, due to the broad approach and the large number (9) of PICO questions and studies included, the assessment of the quality of evidence of each individual publication was not feasible with our limited resources. Third, the guidelines do not indicate the exact drug that should be taken; however, we 
provide the updated evidence-based and consensus-based information for the treating clinicians to make their own choice. Finally, the lack of a Health Economics dimension has to be acknowledged as a limitation of our work. This would need a cost/effectiveness or cost/utility dimension analysis which was beyond the scope of this paper.

A second weakness is that the Belgian reimbursement policy was not taken into account, and reimbursement might be a limiting factor for evidence-based treatments, such as anabolic therapies, which are more expensive than the rest of the treatments. Moreover, some of the anabolic drugs mentioned (abaloparatide or romosozumab) were not yet available in Belgium at the time that the guidelines were developed. However, these points could have been taken into account by the voters.

In conclusion, with these new guidelines, we had the objective of bridging the gap between research and clinical practice (“action-research philosophy” [248]), providing updated high-quality guidelines to clinicians, and let them take their own evidencebased decisions to improve the care of postmenopausal women with osteoporosis.

Acknowledgements: The $\mathrm{BBC}$ members thank the Voting Panel for their valuable contribution.

Authors' contribution: DSR, $\mathrm{CB}$, and $\mathrm{OB}$ wrote the manuscript; $\mathrm{GH}$ and $\mathrm{CB}$ conducted the literature search strategy; DSR and OB did literature review; ML, LL, and CB participated in data collection; PB, JJB, EC, EG, SG, BL, MRL, SR, and OB corrected the manuscript through consecutive comment rounds. All co-authors read and approved the final version of the manuscript.

Funding statement: No funding was received to support this research.

Data statement: This study does not contain any personal data from human or animals' participants performed by any of the authors.

Informed consent: For this type of study formal consent is not required. 


\section{REFERENCES}

[1] J.A. Kanis, C. Cooper, R. Rizzoli, J.-Y.Y. Reginster, Scientific Advisory Board of the European Society for Clinical and Economic Aspects of Osteoporosis (ESCEO) and the Committees of Scientific Advisors and National Societies of the International Osteoporosis Foundation (IOF), European guidance for the diagnosis and management of osteoporosis in postmenopausal women., Osteoporos. Int. 30 (2019) 235-238. https://doi.org/10.1007/s00223-018-00512-x.

[2] J.-J. Body, P. Bergmann, S. Boonen, Y. Boutsen, J.-P. Devogelaer, S. Goemaere, J.-M. Kaufman, S. Rozenberg, J.-Y. Reginster, Evidence-based guidelines for the pharmacological treatment of postmenopausal osteoporosis: a consensus document by the Belgian Bone Club., Osteoporos. Int. 21 (2010) 1657-80. https://doi.org/10.1007/s00198-010-1223-4.

[3] Explanation of the 2011 Oxford Centre for Evidence-Based Medicine (OCEBM) Levels of Evidence (Background Document), Oxford Cent. Evidence-Based Med. Available Http//Www. Cebm. Net/Index. Aspx. (2011).

[4] A. Liberati, D.G. Altman, J. Tetzlaff, C. Mulrow, P.C. Gøtzsche, J.P.A. Ioannidis, M. Clarke, P.J. Devereaux, J. Kleijnen, D. Moher, The PRISMA statement for reporting systematic reviews and meta-analyses of studies that evaluate health care interventions: explanation and elaboration, J. Clin. Epidemiol. 62 (2009) e1-e34. https://doi.org/10.1016/j.jclinepi.2009.06.006.

[5] J.R. Landis, G.G. Koch, An application of hierarchical kappa-type statistics in the assessment of majority agreement among multiple observers., Biometrics. 33 (1977) 363-74.

[6] S.E. Lamb, E.C. Jørstad-Stein, K. Hauer, C. Becker, Development of a common outcome data set for fall injury prevention trials: The Prevention of Falls Network Europe consensus, J. Am. Geriatr. Soc. 53 (2005) 1618-1622. https://doi.org/10.1111/j.1532-5415.2005.53455.x.

[7] P. Barrionuevo, E. Kapoor, N. Asi, F. Alahdab, K. Mohammed, K. Benkhadra, J. Almasri, W. Farah, M. Sarigianni, K. Muthusamy, A. Al Nofal, Q. Haydour, Z. Wang, M.H. Murad, Efficacy of pharmacological therapies for the prevention of fractures in postmenopausal women: A network meta-analysis, J. Clin. Endocrinol. Metab. 104 (2019) 1623-1630. https://doi.org/10.1210/jc.2019-00192.

[8] M.H. Murad, M.T. Drake, R.J. Mullan, K.F. Mauck, L.M. Stuart, M.A. Lane, N.O. Abu Elnour, P.J. Erwin, A. Hazem, M.A. Puhan, V.M. Montori, Comparative effectiveness of drug treatments to prevent fragility fractures: A systematic review and network meta-analysis, J. Clin. Endocrinol. Metab. 97 (2012) 1871-1880. https://doi.org/10.1210/jc.20113060.

[9] J. Zhou, X. Ma, T. Wang, S. Zhai, Comparative efficacy of bisphosphonates in short-term fracture prevention for primary osteoporosis: a systematic review with network meta-analyses, Osteoporos. Int. 27 (2016) 3289-3300. https://doi.org/10.1007/s00198-016-3654-z.

[10] J.Y. Reginster, F. Bianic, R. Campbell, M. Martin, S.A. Williams, L.A. Fitzpatrick, Abaloparatide for risk reduction of nonvertebral and vertebral fractures in postmenopausal women with osteoporosis: a network meta-analysis, Osteoporos. Int. 30 (2019) 1465-1473. https://doi.org/10.1007/s00198-019-04947-2.

[11] et al. Yang L, Kang N, Yang N, Drug efficacies on bone mineral density and fracture rate for the treatment of postmenopausal osteoporosis: A network meta-analysis, Eur. Rev. Med. Pharmacol. Sci. 23 (2019) 2640-2668.

[12] X.C. Yang, Z.H. Deng, T. Wen, W. Luo, W.F. Xiao, R.B. Zhao, Y.S. Li, Network Meta-Analysis of Pharmacological Agents for Osteoporosis Treatment and Fracture Prevention, Cell. Physiol. Biochem. 40 (2016) 781-795. https://doi.org/10.1159/000453138.

[13] G. Wang, L. Sui, P. Gai, G. Li, X. Qi, X. Jiang, The efficacy and safety of vertebral fracture prevention therapies in postmenopausal osteoporosis treatment: Which therapies work best? A network meta-analysis, Bone Jt. Res. 6 (2017) 452-463. https://doi.org/10.1302/2046-3758.67.BJR-2016-0292.R1.

[14] A.G. Ellis, J.Y. Reginster, X. Luo, J.C. Cappelleri, A. Chines, S. Sutradhar, J.P. Jansen, Bazedoxifene versus oral bisphosphonates for the prevention of nonvertebral fractures in postmenopausal women with osteoporosis at higher risk of fracture: A network meta-analysis, Value Heal. 17 (2014) 424-432. https://doi.org/10.1016/j.jval.2014.01.008.

[15] J.P. Jansen, G.J.D. Bergman, J. Huels, M. Olson, The Efficacy of Bisphosphonates in the Prevention of Vertebral, Hip, and Nonvertebral-Nonhip Fractures in Osteoporosis: A Network Meta-Analysis, Semin. Arthritis Rheum. 40 (2011) 27584.e1-2. https://doi.org/10.1016/j.semarthrit.2010.06.001.

[16] N. Freemantle, C. Cooper, A. Diez-Perez, M. Gitlin, H. Radcliffe, S. Shepherd, C. Roux, Results of indirect and mixed treatment comparison of fracture efficacy for osteoporosis treatments: a meta-analysis., Osteoporos. Int. 24 (2013) 20917. https://doi.org/10.1007/s00198-012-2068-9.

[17] J. Sanderson, M. Martyn-St James, J. Stevens, E. Goka, R. Wong, F. Campbell, P. Selby, N. Gittoes, S. Davis, Clinical effectiveness of bisphosphonates for the prevention of fragility fractures: A systematic review and network meta-analysis, Bone. 89 (2016) 52-58. https://doi.org/10.1016/j.bone.2016.05.013.

[18] L.C. Kahwati, R.P. Weber, H. Pan, M. Gourlay, E. LeBlanc, M. Coker-Schwimmer, M. Viswanathan, Vitamin D, Calcium, or Combined Supplementation for the Primary Prevention of Fractures in Community-Dwelling Adults: Evidence Report and Systematic Review for the US Preventive Services Task Force., JAMA. 319 (2018) 1600-1612. https://doi.org/10.1001/jama.2017.21640.

[19] S. Nayak, D.L. Edwards, A.A. Saleh, S.L. Greenspan, Systematic review and meta-analysis of the performance of clinical risk assessment instruments for screening for osteoporosis or low bone density., Osteoporos. Int. 26 (2015) $1543-54$. 
https://doi.org/10.1007/s00198-015-3025-1.

[20] V. Simas, W. Hing, R. Pope, M. Climstein, Effects of water-based exercise on bone health of middle-aged and older adults: a systematic review and meta-analysis, Open Access J. Sport. Med. Volume 8 (2017) 39-60. https://doi.org/10.2147/oajsm.s129182.

[21] R. Zhao, M. Zhao, Z. Xu, The effects of differing resistance training modes on the preservation of bone mineral density in postmenopausal women: a meta-analysis, Osteoporos. Int. 26 (2015) 1605-1618. https://doi.org/10.1007/s00198-0153034-0.

[22] D. Di Ma, L. Wu, Z. He, Effects of walking on the preservation of bone mineral density in perimenopausal and postmenopausal women, Menopause. 20 (2013) 1216-1226. https://doi.org/10.1097/gme.0000000000000100.

[23] A.E. Antoniak, C.A. Greig, The effect of combined resistance exercise training and vitamin D 3 supplementation on musculoskeletal health and function in older adults: a systematic review and meta-analysis, BMJ Open. 7 (2017) e014619. https://doi.org/10.1136/bmjopen-2016-014619.

[24] G.A. Kelley, K.S. Kelley, W.M. Kohrt, Effects of ground and joint reaction force exercise on lumbar spine and femoral neck bone mineral density in postmenopausal women: a meta-analysis of randomized controlled trials, BMC Musculoskelet. Disord. 13 (2012) 177. https://doi.org/10.1186/1471-2474-13-177.

[25] E.A. Marques, J. Mota, J. Carvalho, Exercise effects on bone mineral density in older adults: a meta-analysis of randomized controlled trials, Age (Omaha). 34 (2012) 1493-1515. https://doi.org/10.1007/s11357-011-9311-8.

[26] M. Viswanathan, S. Reddy, N. Berkman, K. Cullen, J.C. Middleton, W.K. Nicholson, L.C. Kahwati, Screening to Prevent Osteoporotic Fractures, JAMA. 319 (2018) 2532. https://doi.org/10.1001/jama.2018.6537.

[27] C.M. Weaver, D.D. Alexander, C.J. Boushey, B. Dawson-Hughes, J.M. Lappe, M.S. LeBoff, S. Liu, A.C. Looker, T.C. Wallace, D.D. Wang, Calcium plus vitamin D supplementation and risk of fractures: an updated meta-analysis from the National Osteoporosis Foundation, Osteoporos. Int. 27 (2016) 367-376. https://doi.org/10.1007/s00198-015-3386-5.

[28] M.J. Bolland, W. Leung, V. Tai, S. Bastin, G.D. Gamble, A. Grey, I.R. Reid, Calcium intake and risk of fracture: Systematic review, BMJ. 351 (2015). https://doi.org/10.1136/bmj.h4580.

[29] J.-G.G. Zhao, X.-T.T. Zeng, J. Wang, L. Liu, Association Between Calcium or Vitamin D Supplementation and Fracture Incidence in Community-Dwelling Older Adults, JAMA. 318 (2017) 2466. https://doi.org/10.1001/jama.2017.19344.

[30] A. Marques, R.J.O. Ferreira, E. Santos, E. Loza, L. Carmona, J.A.P. Da Silva, The accuracy of osteoporotic fracture risk prediction tools: A systematic review and meta-analysis, Ann. Rheum. Dis. 74 (2015) 1958-1967. https://doi.org/10.1136/annrheumdis-2015-207907.

[31] J.R. Lewis, S. Radavelli-Bagatini, L. Rejnmark, J.S. Chen, J.M. Simpson, J.M. Lappe, L. Mosekilde, R.L. Prentice, R.L. Prince, The effects of calcium supplementation on verified coronary heart disease hospitalization and death in postmenopausal women: A collaborative meta-Analysis of randomized controlled trials, J. Bone Miner. Res. 30 (2015) 165-175. https://doi.org/10.1002/jbmr.2311.

[32] M.J. Bolland, A. Avenell, J.A. Baron, A. Grey, G.S. MacLennan, G.D. Gamble, I.R. Reid, Effect of calcium supplements on risk of myocardial infarction and cardiovascular events: Meta-analysis, BMJ. 341 (2010) 289. https://doi.org/10.1136/bmj.c3691.

[33] M.J. Bolland, A. Grey, A. Avenell, Effects of vitamin D supplementation on musculoskeletal health: a systematic review, meta-analysis, and trial sequential analysis, Lancet Diabetes Endocrinol. 6 (2018) 847-858. https://doi.org/10.1016/S2213-8587(18)30265-1.

[34] A. Avenell, J.C.S. Mak, D. O’Connell, Vitamin D and vitamin D analogues for preventing fractures in post-menopausal women and older men, Cochrane Database Syst. Rev. 2014 (2014). https://doi.org/10.1002/14651858.CD000227.pub4.

[35] G.J.D. Bergman, T. Fan, J.T. McFetridge, S.S. Sen, Efficacy of vitamin D3 supplementation in preventing fractures in elderly women: A meta-analysis, Curr. Med. Res. Opin. 26 (2010) 1193-1201. https://doi.org/10.1185/03007991003659814.

[36] J. Marjoribanks, C. Farquhar, H. Roberts, A. Lethaby, J. Lee, Long-term hormone therapy for perimenopausal and postmenopausal women, Cochrane Database Syst. Rev. 2017 (2017). https://doi.org/10.1002/14651858.CD004143.pub5.

[37] S.H. Lee, S.S. Chang, M. Lee, R.C. Chan, C.C. Lee, Risk of osteonecrosis in patients taking bisphosphonates for prevention of osteoporosis: A systematic review and meta-analysis, Osteoporos. Int. 25 (2014) 1131-1139. https://doi.org/10.1007/s00198-013-2575-3.

[38] A. Sharma, A.J. Einstein, A. Vallakati, A. Arbab-Zadeh, M.D. Walker, D. Mukherjee, P. Homel, J.S. Borer, E. Lichstein, Risk of atrial fibrillation with use of oral and intravenous bisphosphonates, Am. J. Cardiol. 113 (2014) 1815-1821. https://doi.org/10.1016/j.amjcard.2014.03.008.

[39] C.J. Crandall, S.J. Newberry, A. Diamant, Y.-W.W. Lim, W.F. Gellad, M.J. Booth, A. Motala, P.G. Shekelle, Comparative effectiveness of pharmacologic treatments to prevent fractures: an updated systematic review., Ann. Intern. Med. 161 (2014) 711-23. https://doi.org/10.7326/M14-0317.

[40] V. Fadda, D. Maratea, S. Trippoli, A. Messori, Gastrointestinal and renal side effects of bisphosphonates: Differentiating between no proof of difference and proof of no difference, J. Endocrinol. Invest. 38 (2015) 189-192. 
https://doi.org/10.1007/s40618-014-0211-5.

[41] X. Jiang, M. Gruner, F. Trémollieres, W. Pluskiewicz, E. Sornay-Rendu, P. Adamczyk, P.F. Schnatz, Diagnostic accuracy of FRAX in predicting the 10-year risk of osteoporotic fractures using the USA treatment thresholds: A systematic review and meta-analysis, Bone. 99 (2017) 20-25. https://doi.org/10.1016/j.bone.2017.02.008.

[42] S. Lee, R. V. Yin, H. Hirpara, N.C. Lee, A. Lee, S. Llanos, O.J. Phung, Increased risk for atypical fractures associated with bisphosphonate use, Fam. Pract. 32 (2015) 276-281. https://doi.org/10.1093/fampra/cmu088.

[43] D.H. Kim, J.R. Rogers, L.A. Fulchino, C.A. Kim, D.H. Solomon, S.C. Kim, Bisphosphonates and Risk of Cardiovascular Events: A Meta-Analysis, PLoS One. 10 (2015) e0122646. https://doi.org/10.1371/journal.pone.0122646.

[44] L. Zhang, Y. Pang, Y. Shi, M. Xu, X. Xu, J. Zhang, L. Ji, D. Zhao, Indirect comparison of teriparatide, denosumab, and oral bisphosphonates for the prevention of vertebral and nonvertebral fractures in postmenopausal women with osteoporosis, Menopause. 22 (2015) 1021-1025. https://doi.org/10.1097/GME.0000000000000466.

[45] H.F. Gu, L.J. Gu, Y. Wu, X.H. Zhao, Q. Zhang, Z.R. Xu, Y.M. Yang, Efficacy and Safety of Denosumab in Postmenopausal Women with Osteoporosis, Med. (United States). 94 (2015) e1674. https://doi.org/10.1097/MD.0000000000001674.

[46] G. Kranenburg, J.W. Bartstra, M. Weijmans, P.A. de Jong, W.P. Mali, H.J. Verhaar, F.L.J. Visseren, W. Spiering, Bisphosphonates for cardiovascular risk reduction: A systematic review and meta-analysis, Atherosclerosis. 252 (2016) 106-115. https://doi.org/10.1016/j.atherosclerosis.2016.06.039.

[47] C. Wang, Efficacy and Safety of Zoledronic Acid for Treatment of Postmenopausal Osteoporosis: A Meta-Analysis of Randomized Controlled Trials, Am. J. Ther. 24 (2017) e544-e552. https://doi.org/10.1097/MJT.0000000000000415.

[48] T. Saito, J.M. Sterbenz, S. Malay, L. Zhong, M.P. MacEachern, K.C. Chung, Effectiveness of anti-osteoporotic drugs to prevent secondary fragility fractures: systematic review and meta-analysis, Osteoporos. Int. 28 (2017) 3289-3300. https://doi.org/10.1007/s00198-017-4175-0.

[49] L. Peng, Q. Luo, H. Lu, Efficacy and safety of bazedoxifene in postmenopausal women with osteoporosis: A systematic review and meta-analysis., Medicine (Baltimore). 96 (2017) e8659. https://doi.org/10.1097/MD.0000000000008659.

[50] J.A. Kanis, H. Johansson, A. Oden, E. V McCloskey, A meta-analysis of the efficacy of raloxifene on all clinical and vertebral fractures and its dependency on FRAX®, Bone. 47 (2010) 729-735. https://doi.org/10.1016/j.bone.2010.06.009.

[51] D.C. MacKey, D.M. Black, D.C. Bauer, E. V. McCloskey, R. Eastell, P. Mesenbrink, J.R. Thompson, S.R. Cummings, Effects of antiresorptive treatment on nonvertebral fracture outcomes, J. Bone Miner. Res. 26 (2011) 2411-2418. https://doi.org/10.1002/jbmr.446.

[52] A. Moayyeri, J.E. Adams, R.A. Adler, M.-A.M.-A.A. Krieg, D. Hans, J. Compston, E.M. Lewiecki, Quantitative ultrasound of the heel and fracture risk assessment: An updated meta-analysis, Osteoporos. Int. 23 (2012) $143-153$. https://doi.org/10.1007/s00198-011-1817-5.

[53] R.B. Hopkins, R. Goeree, E. Pullenayegum, J.D. Adachi, A. Papaioannou, F. Xie, L. Thabane, The relative efficacy of nine osteoporosis medications for reducing the rate of fractures in post-menopausal women, BMC Musculoskelet. Disord. 12 (2011). https://doi.org/10.1186/1471-2474-12-209.

[54] Y.H. Lee, G.G. Song, Efficacy and Safety of Monthly $150 \mathrm{mg}$ Oral Ibandronate in Women with Postmenopausal Osteoporosis: A Systematic Review and Meta-analysis of Randomized Controlled Trials, Korean J. Intern. Med. 26 (2011) 340. https://doi.org/10.3904/kjim.2011.26.3.340.

[55] E. Barrett-Connor, A.S. Swern, C.M. Hustad, H.G. Bone, U.A. Liberman, S. Papapoulos, H. Wang, A. De Papp, A.C. Santora, Alendronate and atrial fibrillation: A meta-analysis of randomized placebo-controlled clinical trials, Osteoporos. Int. 23 (2012) 233-245. https://doi.org/10.1007/s00198-011-1546-9.

[56] S.L. Han, S.L. Wan, Effect of teriparatide on bone mineral density and fracture in postmenopausal osteoporosis: Metaanalysis of randomised controlled trials, Int. J. Clin. Pract. 66 (2012) 199-209. https://doi.org/10.1111/j.1742 1241.2011.02837.x.

[57] Y. Liu, S. Zhao, W. Chen, F. Hu, L. Zhu, Q. Zhang, Y. Zhao, Bisphosphonate use and the risk of breast cancer: A metaanalysis of published literature, Clin. Breast Cancer. 12 (2012) 276-281. https://doi.org/10.1016/j.clbc.2012.04.003.

[58] J. Andrici, M. Tio, G.D. Eslick, Meta-analysis: Oral bisphosphonates and the risk of oesophageal cancer, Aliment. Pharmacol. Ther. 36 (2012) 708-716. https://doi.org/10.1111/apt.12041.

[59] L. Silva-Fernández, M.P. Rosario, J.A. Martínez-López, L. Carmona, E. Loza, Denosumab for the treatment of osteoporosis: A systematic literature review, Reumatol. Clin. 9 (2013) 42-52. https://doi.org/10.1016/j.reuma.2012.06.007.

[60] K. Sun, J.M. Liu, H.X. Sun, N. Lu, G. Ning, Bisphosphonate treatment and risk of esophageal cancer: A meta-analysis of observational studies, Osteoporos. Int. 24 (2013) 279-286. https://doi.org/10.1007/s00198-012-2158-8.

[61] L. Gedmintas, D.H. Solomon, S.C. Kim, Bisphosphonates and risk of subtrochanteric, femoral shaft, and atypical femur fracture: A systematic review and meta-analysis, J. Bone Miner. Res. 28 (2013) 1729-1737. https://doi.org/10.1002/jbmr.1893.

[62] A. Migliore, S. Broccoli, U. Massafra, M. Cassol, B. Frediani, Ranking antireabsorptive agents to prevent vertebral 
fractures in postmenopausal osteoporosis by mixed treatment comparison meta-analysis., Eur. Rev. Med. Pharmacol. Sci. 17 (2013) 658-67.

[63] H. Johansson, A. Odén, J.A. Kanis, E. V. McCloskey, H.A. Morris, C. Cooper, S. Vasikaran, IFCC-IOF Joint Working Group on Standardisation of Biochemical Markers of Bone Turnover, A meta-analysis of reference markers of bone turnover for prediction of fracture, Calcif. Tissue Int. 94 (2014) 560-567. https://doi.org/10.1007/s00223-014-9842-y.

[64] A.J. Serrano, L. Begoña, E. Anitua, R. Cobos, G. Orive, Systematic review and meta-analysis of the efficacy and safety of alendronate and zoledronate for the treatment of postmenopausal osteoporosis, Gynecol. Endocrinol. 29 (2013) 10051014. https://doi.org/10.3109/09513590.2013.813468.

[65] L.X. Chen, G.Z. Ning, Z.R. Zhou, Y.L. Li, D. Zhang, Q.L. Wu, T.S. Zhang, L. Cheng, S.Q. Feng, The carcinogenicity of alendronate in patients with osteoporosis: Evidence from cohort studies, PLoS One. 10 (2015) e0123080. https://doi.org/10.1371/journal.pone.0123080.

[66] A. Fontalis, E. Kenanidis, E. Prousali, M. Potoupnis, E. Tsiridis, Safety and efficacy of denosumab in osteoporotic patients previously treated with other medications: a systematic review and meta-analysis, Expert Opin. Drug Saf. 17 (2018) 413 428. https://doi.org/10.1080/14740338.2018.1430764.

[67] Y. Liu, Y. Cao, S. Zhang, W. Zhang, B. Zhang, Q. Tang, Z. Li, J. Wu, Romosozumab treatment in postmenopausal women with osteoporosis: a meta-analysis of randomized controlled trials., Climacteric. 21 (2018) 189-195. https://doi.org/10.1080/13697137.2018.1433655.

[68] M. Zhou, Y. Zheng, J. Li, J. Wu, W. Xu, L. Cui, W. Yao, Y. Liu, Upper gastrointestinal safety and tolerability of oral alendronate: A meta-analysis, Exp. Ther. Med. 11 (2016) 289-296. https://doi.org/10.3892/etm.2015.2848.

[69] H.A. Fink, R. MacDonald, M.L. Forte, C.E. Rosebush, K.E. Ensrud, J.T. Schousboe, V.A. Nelson, K. Ullman, M. Butler, C.M. Olson, B.C. Taylor, M. Brasure, T.J. Wilt, Long-Term Drug Therapy and Drug Discontinuations and Holidays for Osteoporosis Fracture Prevention, Ann. Intern. Med. 171 (2019) 37. https://doi.org/10.7326/M19-0533.

[70] A. Díez-Pérez, F. Marin, E.F. Eriksen, D.L. Kendler, J.H. Krege, M. Delgado-Rodríguez, Effects of teriparatide on hip and upper limb fractures in patients with osteoporosis: A systematic review and meta-analysis, Bone. 120 (2019) 1-8. https://doi.org/10.1016/j.bone.2018.09.020.

[71] S. Nayak, S.L. Greenspan, A systematic review and meta-analysis of the effect of bisphosphonate drug holidays on bone mineral density and osteoporotic fracture risk, Osteoporos. Int. 30 (2019) 705-720. https://doi.org/10.1007/s00198-0184791-3.

[72] Fraser, K.N. Vogt, R. Adachi, L. Thabane, Fracture risk associated with continuation versus discontinuation of bisphosphonates after 5 years of therapy in patients with primary osteoporosis: a systematic review and meta-analysis, Ther. Clin. Risk Manag. (2011) 157. https://doi.org/10.2147/TCRM.S19385.

[73] J.-H. Byun, S. Jang, S. Lee, S. Park, H.K. Yoon, B.-H. Yoon, Y.-C. Ha, The Efficacy of Bisphosphonates for Prevention of Osteoporotic Fracture: An Update Meta-analysis, J. Bone Metab. 24 (2017) 37. https://doi.org/10.11005/jbm.2017.24.1.37.

[74] A. Varahra, I.B. Rodrigues, J.C. MacDermid, D. Bryant, T. Birmingham, Exercise to improve functional outcomes in persons with osteoporosis: a systematic review and meta-analysis, Osteoporos. Int. 29 (2018) 265-286. https://doi.org/10.1007/s00198-017-4339-y.

[75] S.Y. Lee, S.H. Jung, S.U. Lee, Y.C. Ha, J.Y. Lim, Can Bisphosphonates Prevent Recurrent Fragility Fractures? A Systematic Review and Meta-Analysis of Randomized Controlled Trials, J. Am. Med. Dir. Assoc. 19 (2018) 384-390.e1. https://doi.org/10.1016/j.jamda.2018.02.005.

[76] S.Y. Kim, M.J. Kim, S.M. Cadarette, D.H. Solomon, Bisphosphonates and risk of atrial fibrillation: a meta-analysis, Arthritis Res. Ther. 12 (2010) R30. https://doi.org/10.1186/ar2938.

[77] R. Bhuriya, M. Singh, J. Molnar, R. Arora, S. Khosla, Bisphosphonate use in women and the risk of atrial fibrillation: a systematic review and meta-analysis., Int. J. Cardiol. 142 (2010) 213-7. https://doi.org/10.1016/j.ijcard.2009.11.041.

[78] C. von Keyserlingk, R. Hopkins, A. Anastasilakis, K. Toulis, R. Goeree, J.E. Tarride, F. Xie, Clinical Efficacy and Safety of Denosumab in Postmenopausal Women with Low Bone Mineral Density and Osteoporosis: A Meta-Analysis, Semin. Arthritis Rheum. 41 (2011) 178-186. https://doi.org/10.1016/j.semarthrit.2011.03.005.

[79] J. Zhang, R. Wang, Y.L. Zhao, X.H. Sun, H.X. Zhao, L. Tan, D.C. Chen, X. Hai-Bin, Efficacy of intravenous zoledronic acid in the prevention and treatment of osteoporosis: A meta-analysis, Asian Pac. J. Trop. Med. 5 (2012) $743-748$. https://doi.org/10.1016/S1995-7645(12)60118-7.

[80] Y.H. Oh, C. Yoon, S.M. Park, Bisphosphonate use and gastrointestinal tract cancer risk: Meta-analysis of observational studies, World J. Gastroenterol. 18 (2012) 5779-5788. https://doi.org/10.3748/wjg.v18.i40.5779.

[81] S. Singh, A.G. Singh, M.H. Murad, P.J. Limburg, Bisphosphonates are associated with reduced risk of colorectal cancer: A systematic review and meta-analysis, Clin. Gastroenterol. Hepatol. 11 (2013) 232-9.e1. https://doi.org/10.1016/j.cgh.2012.11.026.

[82] G. Yang, H. Hu, R. Zeng, J. Huang, Oral Bisphosphonates and the Risk of Colorectal Cancer, J. Clin. Gastroenterol. 47 (2013) 741-748. https://doi.org/10.1097/MCG.0b013e31829e446b.

[83] Z. Zhou, C. Chen, J. Zhang, X. Ji, L. Liu, G. Zhang, X. Cao, P. Wang, Safety of denosumab in postmenopausal women 
with osteoporosis or low bone mineral density: A meta-analysis, Int. J. Clin. Exp. Pathol. 7 (2014) $2113-2122$.

[84] M. Liu, L. Guo, Y. Pei, N. Li, M. Jin, L. Ma, Y. Liu, B. Sun, C. Li, Efficacy of zoledronic acid in treatment of osteoporosis in men and women-a meta-analysis, Int. J. Clin. Exp. Med. 8 (2015) 3855-3861.

[85] K. Rong, X.Y. Liu, X.H. Wu, X.L. Li, Q.Q. Xia, J. Chen, X.F. Yin, Increasing level of leisure physical activity could reduce the risk of hip fracture in older women: A dose-response meta-analysis of prospective cohort studies, Med. (United States). 95 (2016) e2984. https://doi.org/10.1097/MD.0000000000002984.

[86] W. Li, W. Chen, Y. Lin, The efficacy of parathyroid hormone analogues in combination with bisphosphonates for the treatment of osteoporosis: A meta-analysis of randomized controlled trials, Med. (United States). 94 (2015) e1156. https://doi.org/10.1097/MD.0000000000001156.

[87] E. Wright, P.T. Schofield, M. Molokhia, Bisphosphonates and evidence for association with esophageal and gastric cancer: a systematic review and meta-analysis, BMJ Open. 5 (2015) e007133. https://doi.org/10.1136/bmjopen-2014-007133.

[88] Y. Zhang, L. Zhang, S. Li, F. Sun, J. Li, A. Ke, X. Chen, X. Zhang, L. Xu, J. Duan, G. Zhang, D. Li, G. Ding, L. Qin, C. Wang, Effect of denosumab, a fully human monoclonal antibody to RANKL, on bone mineral density and fractures: A meta-analysis, Int. J. Clin. Exp. Med. 10 (2017) 5931-5940.

[89] D. Cai, J. Qin, G. Chen, W. Feng, J. Liu, Bisphosphonates use and risk of gastric cancer: An updated meta-analysis of cohort and case-control studies, Minerva Med. 108 (2017) 464-472. https://doi.org/10.23736/S0026-4806.17.05055-8.

[90] Y.J. Ou, H.F. Chiu, Y.H. Wong, C.C. Yang, Y.H. Yang, Bisphosphonate use and the risk of breast cancer: a meta-analysis of observational studies, Pharmacoepidemiol. Drug Saf. 26 (2017) 1286-1295. https://doi.org/10.1002/pds.4302.

[91] M. Khalili, A. Hosseinzadeh, H.M. Kiavandani, N. Khanjani, Effects of Bazedoxifene on Bone Mineral Density and Fracture in Post-Menopausal Osteoporotic Women: a Systematic Review and Meta-Analysis, Clin. Rev. Bone Miner. Metab. 16 (2018) 22-32. https://doi.org/10.1007/s12018-018-9241-4.

[92] Y. Deng, Z. Zhang, X. Jia, W. Cheng, X. Zhou, Y. Liu, M. Wang, Oral bisphosphonates and incidence of cancers in patients with osteoporosis: a systematic review and meta-analysis, Arch. Osteoporos. 14 (2019) 1. https://doi.org/10.1007/s11657-018-0552-3.

[93] T. Wang, Z. Xuan, R. Li, L. Song, Y. Dou, J. Ren, X. Jia, L. Lu, Efficacy and safety of denosumab and teriparatide treatment for osteoporosis: A systematic review and meta-analysis, Int. J. Clin. Exp. Med. 10 (2017) 5949-5956.

[94] L. Liu, C. Li, P. Yang, J. Zhu, D. Gan, L. Bu, M. Zhang, C. Sheng, H. Li, S. Qu, Association between alendronate and atypical femur fractures: a meta-analysis, Endocr. Connect. 4 (2014) 58-64. https://doi.org/10.1530/ec-14-0120.

[95] T.E. Howe, B. Shea, L.J. Dawson, F. Downie, A. Murray, C. Ross, R.T. Harbour, L.M. Caldwell, G. Creed, Exercise for preventing and treating osteoporosis in postmenopausal women, Cochrane Database Syst. Rev. 2011 (2011) 1-167. https://doi.org/10.1002/14651858.CD000333.pub2.

[96] R. Zhao, M. Zhang, Q. Zhang, The Effectiveness of Combined Exercise Interventions for Preventing Postmenopausal Bone Loss: A Systematic Review and Meta-analysis, J. Orthop. Sport. Phys. Ther. 47 (2017) 241-251. https://doi.org/10.2519/jospt.2017.6969.

[97] P. Barrionuevo, M.R. Gionfriddo, A. Castaneda-Guarderas, C. Zeballos-Palacios, P. Bora, K. Mohammed, K. Benkhadra, M. Sarigianni, M.H. Murad, Women’s Values and Preferences Regarding Osteoporosis Treatments: A Systematic Review., J. Clin. Endocrinol. Metab. 104 (2019) 1631-1636. https://doi.org/10.1210/jc.2019-00193.

[98] E.B. Gausden, B.U. Nwachukwu, J.J. Schreiber, D.G. Lorich, J.M. Lane, Opportunistic use of CT imaging for osteoporosis screening and bone density assessment: A qualitative systematic review, J. Bone Jt. Surg. - Am. Vol. 99 (2017) 1580-1590. https://doi.org/10.2106/JBJS.16.00749.

[99] K.H. Rubin, T. Friis-Holmberg, A.P. Hermann, B. Abrahamsen, K. Brixen, Risk assessment tools to identify women with increased risk of osteoporotic fracture: Complexity or simplicity? A systematic review, J. Bone Miner. Res. 28 (2013) 1701-1717. https://doi.org/10.1002/jbmr.1956.

[100] T. Funck-Brentano, E. Biver, F. Chopin, B. Bouvard, G. Coiffier, J.C. Souberbielle, P. Garnero, C. Roux, Clinical Utility of Serum Bone Turnover Markers in Postmenopausal Osteoporosis Therapy Monitoring: A Systematic Review, Semin. Arthritis Rheum. 41 (2011) 157-169. https://doi.org/10.1016/j.semarthrit.2011.01.005.

[101] J.-H.H. Lee, Y.K.E. Lee, S.-H.H. Oh, J. Ahn, Y.K.E. Lee, J.H. Pyo, Y.Y. Choi, D.-Y.Y.D.-Y. Kim, S.-C.C. Bae, Y.-K.K. Sung, D.-Y.Y.D.-Y. Kim, A systematic review of diagnostic accuracy of vertebral fracture assessment (VFA) in postmenopausal women and elderly men, Osteoporos. Int. 27 (2016) 1691-1699. https://doi.org/10.1007/s00198-0153436-z.

[102] M.P. Høiberg, K.H. Rubin, A.P. Hermann, K. Brixen, B. Abrahamsen, Diagnostic devices for osteoporosis in the general population: A systematic review., Bone. 92 (2016) 58-69. https://doi.org/10.1016/j.bone.2016.08.011.

[103] J.A. Kanis, N.C. Harvey, C. Cooper, H. Johansson, A. Odén, E. V. McCloskey, The Advisory Board of the National Osteoporosis Guideline Group, K.E. Poole, N. Gittoes, S. Hope, A systematic review of intervention thresholds based on FRAX, Arch. Osteoporos. 11 (2016) 25. https://doi.org/10.1007/s11657-016-0278-z.

[104] K. Thomsen, D.B. Jepsen, L. Matzen, A.P. Hermann, T. Masud, J. Ryg, Is calcaneal quantitative ultrasound useful as a prescreen stratification tool for osteoporosis?, Osteoporos. Int. 26 (2015) 1459-1475. https://doi.org/10.1007/s00198-014- 
3012-y.

[105] C.J. Crandall, Risk Assessment Tools for Osteoporosis Screening in Postmenopausal Women: A Systematic Review., Curr. Osteoporos. Rep. 13 (2015) 287-301. https://doi.org/10.1007/s11914-015-0282-z.

[106] D. Minniti, O. Davini, M.R. Gualano, M.M. Gianino, Techniques for diagnosing osteoporosis: A systematic review of cost-effectiveness studies, Int. J. Technol. Assess. Health Care. 30 (2014) 273-281. https://doi.org/10.1017/S0266462314000257.

[107] S. Nayak, D.L. Edwards, A.A. Saleh, S.L. Greenspan, Performance of risk assessment instruments for predicting osteoporotic fracture risk: a systematic review., Osteoporos. Int. 25 (2014) 23-49. https://doi.org/10.1007/s00198-0132504-5.

[108] E.F. Eriksen, A. Díez-Pérez, S. Boonen, Update on long-term treatment with bisphosphonates for postmenopausal osteoporosis: A systematic review, Bone. 58 (2014) 126-135. https://doi.org/10.1016/j.bone.2013.09.023.

[109] P. Anagnostis, S.A. Paschou, G. Mintziori, I. Ceausu, H. Depypere, I. Lambrinoudaki, A. Mueck, F.R. Pérez-López, M. Rees, L.M. Senturk, T. Simoncini, J.C. Stevenson, P. Stute, F.A. Trémollieres, D.G. Goulis, Drug holidays from bisphosphonates and denosumab in postmenopausal osteoporosis: EMAS position statement., Maturitas. 101 (2017) 2330. https://doi.org/10.1016/j.maturitas.2017.04.008.

[110] R. Lorenc, P. Głuszko, E. Franek, M. Jabłoński, M. Jaworski, E. Kalinka-Warzocha, E.E. Karczmarewicz, T. Kostka, K Księżopolska-Orłowska, E. Marcinowska-Suchowierska, W. Misiorowski, A. Więcek, K. Księzopolska-Orłowska, E. Marcinowska-Suchowierska, W. Misiorowski, A. Więcek, Guidelines for the diagnosis and management of osteoporosis in Poland. Update 2017, Endokrynol. Pol. 68 (2017) 604-609. https://doi.org/10.5603/EP.2017.0062.

[111] S.J. Curry, A.H. Krist, D.K. Owens, M.J. Barry, A.B. Caughey, K.W. Davidson, C.A. Doubeni, J.W. Epling, A.R. Kemper M. Kubik, C.S. Landefeld, C.M. Mangione, M.G. Phipps, M. Pignone, M. Silverstein, M.A. Simon, C.-W. Tseng, J.B. Wong, Screening for Osteoporosis to Prevent Fractures, JAMA. 319 (2018) 2521. https://doi.org/10.1001/jama.2018.7498.

[112] M. Brincat, J. Calleja-Agius, C.T. Erel, M. Gambacciani, I. Lambrinoudaki, M.H. Moen, K. Schenck-Gustafsson, F. Tremollieres, S. Vujovic, M. Rees, S. Rozenberg, EMAS position statement: Bone densitometry screening for osteoporosis, Maturitas. 68 (2011) 98-101. https://doi.org/10.1016/j.maturitas.2010.09.009.

[113] S. Vasikaran, R. Eastell, O. Bruyère, A.J. Foldes, P. Garnero, A. Griesmacher, M. McClung, H.A. Morris, S. Silverman, T. Trenti, D.A. Wahl, C. Cooper, J.A. Kanis, Markers of bone turnover for the prediction of fracture risk and monitoring of osteoporosis treatment: A need for international reference standards, Osteoporos. Int. 22 (2011) 391-420. https://doi.org/10.1007/s00198-010-1501-1.

[114] J.-J. Body, P. Bergmann, S. Boonen, Y. Boutsen, O. Bruyere, J.-P. Devogelaer, S. Goemaere, N. Hollevoet, J.-M. Kaufman, K. Milisen, S. Rozenberg, J.-Y. Reginster, Non-pharmacological management of osteoporosis: a consensus of the Belgian Bone Club., Osteoporos. Int. 22 (2011) 2769-88. https://doi.org/10.1007/s00198-011-1545-X.

[115] N. Mendoza, R. Sánchez-Borrego, J. Villero, F. Baró, J. Calaf, M.J. Cancelo, P. Coronado, A. Estévez, J.M. FernándezMoya, S. González, P. Llaneza, J.L. Neyro, J. Del Pino, E. Rodríguez, E. Ruiz, A. Cano, 2013 Up-date of the consensus statement of the Spanish Menopause Society on postmenopausal osteoporosis, Maturitas. 76 (2013) 99-107. https://doi.org/10.1016/j.maturitas.2013.05.021.

[116] R. Rizzoli, S. Boonen, M.-L.M.-L.L.M.-L. Brandi, O. Bruyère, C. Cooper, J.A.A. Kanis, J.-M.J.-M.M.J.-M. Kaufman, J.D.D. Ringe, G. Weryha, J.-Y.J.-Y.Y. Reginster, Vitamin D supplementation in elderly or postmenopausal women: a 2013 update of the 2008 recommendations from the European Society for Clinical and Economic Aspects of Osteoporosis and Osteoarthritis (ESCEO), Curr. Med. Res. Opin. 29 (2013) 305-313. https://doi.org/10.1185/03007995.2013.766162.

[117] R. Nuti, M.L. Brandi, G. Checchia, O. Di Munno, L. Dominguez, P. Falaschi, C.E. Fiore, G. Iolascon, S. Maggi, R. Michieli, S. Migliaccio, S. Minisola, M. Rossini, G. Sessa, U. Tarantino, A. Toselli, G.C. Isaia, Guidelines for the management of osteoporosis and fragility fractures, Intern. Emerg. Med. 14 (2019) 85-102. https://doi.org/10.1007/s11739-018-1874-2.

[118] R. Eastell, C.J. Rosen, D.M. Black, A.M. Cheung, M.H. Murad, D. Shoback, M. Hassan Murad, D. Shoback, Pharmacological Management of Osteoporosis in Postmenopausal Women: An Endocrine Society* Clinical Practice Guideline, J. Clin. Endocrinol. Metab. 104 (2019) 1595-1622. https://doi.org/10.1210/jc.2019-00221.

[119] T.J. Aspray, C. Bowring, W. Fraser, N. Gittoes, M.K. Javaid, H. Macdonald, S. Patel, P. Selby, N. Tanna, R.M. Francis, National osteoporosis society vitamin D Guideline Summary, Age Ageing. 43 (2014) 592-595 https://doi.org/10.1093/ageing/afu093.

[120] K. Briot, C. Roux, T. Thomas, H. Blain, D. Buchon, R. Chapurlat, F. Debiais, J.M. Feron, J.B. Gauvain, P. Guggenbuhl, E. Legrand, A.M. Lehr-Drylewicz, E. Lespessailles, F. Tremollieres, G. Weryha, B. Cortet, 2018 update of French recommendations on the management of postmenopausal osteoporosis, Jt. Bone Spine. 85 (2018) 519-530. https://doi.org/10.1016/j.jbspin.2018.02.009.

[121] A. Qaseem, M.A. Forciea, R.M. McLean, T.D. Denberg, Treatment of Low Bone Density or Osteoporosis to Prevent Fractures in Men and Women: A Clinical Practice Guideline Update From the American College of Physicians, Ann. Intern. Med. 166 (2017) 818. https://doi.org/10.7326/M15-1361.

[122] E. Tsourdi, B. Langdahl, M. Cohen-Solal, B. Aubry-Rozier, E.F. Eriksen, N. Guañabens, B. Obermayer-Pietsch, S.H. Ralston, R. Eastell, M.C. Zillikens, Discontinuation of Denosumab therapy for osteoporosis: A systematic review and position statement by ECTS, Bone. 105 (2017) 11-17. https://doi.org/10.1016/j.bone.2017.08.003. 
[123] A.M. Rodrigues, H. Canhão, A. Marques, C. Ambrósio, J. Borges, P. Coelho, L. Costa, S. Fernandes, I. Gonçalves, M. Gonçalves, M. Guerra, M.L. Marques, S. Pimenta, P. Pinto, G. Sequeira, E. Simões, L. Teixeira, C. Vaz, E. Vieira-Sousa, R. Vieira, F. Alvarenga, F. Araújo, A. Barcelos, F. Barcelos, R. Barros, M. Bernardes, J. Canas da Silva, A. Cordeiro, M. Costa, L. Cunha-Miranda, M. Cruz, A.C. Duarte, C. Duarte, A. Faustino, G. Figueiredo, J.E. Fonseca, C. Furtado, J. Gomes, C. Lopes, A.F. Mourão, M. Oliveira, F.M. Pimentel-Santos, A. Ribeiro, T. Sampaio da Nóvoa, M. Santiago, C. Silva, A. Silva-Dinis, S. Sousa, J. Tavares-Costa, G. Terroso, A. Vilar, J.C. Branco, V. Tavares, J.C. Romeu, J. da Silva, Portuguese recommendations for the prevention, diagnosis and management of primary osteoporosis - 2018 update., Acta Reumatol. Port. 43 (2018) 10-31.

[124] P. Makras, A.D. Anastasilakis, G. Antypas, E. Chronopoulos, E.G. Kaskani, A. Matsouka, D.K. Patrikos, K.D. Stathopoulos, S. Tournis, G. Trovas, C. Kosmidis, The 2018 Guidelines for the diagnosis and treatment of osteoporosis in Greece, Arch. Osteoporos. 14 (2019) 39. https://doi.org/10.1007/s11657-019-0584-3.

[125] D.C. Grossman, S.J. Curry, D.K. Owens, M.J. Barry, A.B. Caughey, K.W. Davidson, C.A. Doubeni, J.W. Epling, A.R. Kemper, A.H. Krist, M. Kubik, S. Landefeld, C.M. Mangione, M. Silverstein, M.A. Simon, C.-W. Tseng, Vitamin D, Calcium, or Combined Supplementation for the Primary Prevention of Fractures in Community-Dwelling Adults, JAMA. 319 (2018) 1592. https://doi.org/10.1001/jama.2018.3185.

[126] J.A. Kanis, C. Cooper, R. Rizzoli, J.-Y. Reginster, Executive summary of European guidance for the diagnosis and management of osteoporosis in postmenopausal women, Aging Clin. Exp. Res. 31 (2019) 15-17. https://doi.org/10.1007/s40520-018-1109-4.

[127] B.C. Silva, S.B. Broy, S. Boutroy, J.T. Schousboe, J.A. Shepherd, W.D. Leslie, Fracture Risk Prediction by Non-BMD DXA Measures: The 2015 ISCD Official Positions Part 2: Trabecular Bone Score, J. Clin. Densitom. 18 (2015) 309-330. https://doi.org/10.1016/j.jocd.2015.06.008.

[128] P.M. Camacho, S.M. Petak, N. Binkley, B.L. Clarke, S.T. Harris, D.L. Hurley, M. Kleerekoper, E.M. Lewiecki, P.D. Miller, H.S. Narula, R. Pessah-Pollack, V. Tangpricha, S.J. Wimalawansa, N.B. Watts, American association of clinical endocrinologists and American college of endocrinology clinical practice guidelines for the diagnosis and treatment of postmenopausal osteoporosis - 2016, Endocr. Pract. 22 (2016) 1-42. https://doi.org/10.4158/EP161435.GL.

[129] S.L. Kopecky, D.C. Bauer, M. Gulati, J.W. Nieves, A.J. Singer, P.P. Toth, J.A. Underberg, T.C. Wallace, C.M. Weaver, Lack of Evidence Linking Calcium With or Without Vitamin D Supplementation to Cardiovascular Disease in Generally Healthy Adults: A Clinical Guideline From the National Osteoporosis Foundation and the American Society for Preventive Cardiology, Ann. Intern. Med. 165 (2016) 867. https://doi.org/10.7326/M16-1743.

[130] N.C. Harvey, E. Biver, J.-M. Kaufman, J. Bauer, J. Branco, M.L. Brandi, O. Bruyère, V. Coxam, A. Cruz-Jentoft, E. Czerwinski, H. Dimai, P. Fardellone, F. Landi, J.-Y. Reginster, B. Dawson-Hughes, J.A. Kanis, R. Rizzoli, C. Cooper, The role of calcium supplementation in healthy musculoskeletal ageing, Osteoporos. Int. 28 (2017) 447-462. https://doi.org/10.1007/s00198-016-3773-6.

[131] A. Diez-Perez, K.E. Naylor, B. Abrahamsen, D. Agnusdei, M.L. Brandi, C. Cooper, E. Dennison, E.F. Eriksen, D.T. Gold, N. Guañabens, P. Hadji, M. Hiligsmann, R. Horne, R. Josse, J.A. Kanis, B. Obermayer-Pietsch, D. Prieto-Alhambra, J.Y. Reginster, R. Rizzoli, S. Silverman, M.C. Zillikens, R. Eastell, International Osteoporosis Foundation and European Calcified Tissue Society Working Group. Recommendations for the screening of adherence to oral bisphosphonates, Osteoporos. Int. 28 (2017) 767-774. https://doi.org/10.1007/s00198-017-3906-6.

[132] J. Compston, A. Cooper, C. Cooper, N. Gittoes, C. Gregson, N. Harvey, S. Hope, J.A. Kanis, E. V. McCloskey, K.E.S.S. Poole, D.M. Reid, P. Selby, F. Thompson, A. Thurston, N. Vine, UK clinical guideline for the prevention and treatment of osteoporosis, Arch. Osteoporos. 12 (2017) 43. https://doi.org/10.1007/s11657-017-0324-5.

[133] R.J. Ward, C.C. Roberts, J.T. Bencardino, E. Arnold, S.J. Baccei, R.C. Cassidy, E.Y. Chang, M.G. Fox, B.S. Greenspan, S Gyftopoulos, M.G. Hochman, D.N. Mintz, J.S. Newman, C. Reitman, Z.S. Rosenberg, N.A. Shah, K.M. Small, B.N. Weissman, ACR Appropriateness Criteria ${ }^{\circledR}$ Osteoporosis and Bone Mineral Density, J. Am. Coll. Radiol. 14 (2017) S189S202. https://doi.org/10.1016/j.jacr.2017.02.018.

[134] J.A. Kanis, N.C. Harvey, E. McCloskey, O. Bruyère, N. Veronese, M. Lorentzon, C. Cooper, R. Rizzoli, G. Adib, N. AlDaghri, C. Campusano, M. Chandran, B. Dawson-Hughes, K. Javaid, F. Jiwa, H. Johansson, J.K. Lee, E. Liu, D. Messina, O. Mkinsi, D. Pinto, D. Prieto-Alhambra, K. Saag, W. Xia, L. Zakraoui, J.-Y.Y. Reginster, Algorithm for the management of patients at low, high and very high risk of osteoporotic fractures, Osteoporos. Int. 31 (2020) 1-12. https://doi.org/10.1007/s00198-019-05176-3.

[135] E.M. Lewiecki, R. V Dinavahi, M. Lazaretti-Castro, P.R. Ebeling, J.D. Adachi, A. Miyauchi, E. Gielen, C.E. Milmont, C. Libanati, A. Grauer, One Year of Romosozumab Followed by Two Years of Denosumab Maintains Fracture Risk Reductions: Results of the FRAME Extension Study, J. Bone Miner. Res. 34 (2019) 419-428. https://doi.org/10.1002/jbmr.3622.

[136] R.B. Conley, G. Adib, R.A. Adler, K.E. Akesson, I.M. Alexander, K.C. Amenta, R.D. Blank, W.T. Brox, E.E. Carmody, K. Chapman-Novakofski, B.L. Clarke, K.M. Cody, C. Cooper, C.J. Crandall, D.R. Dirschl, T.J. Eagen, A.L. Elderkin, M. Fujita, S.L. Greenspan, P. Halbout, M.C. Hochberg, M. Javaid, K.J. Jeray, A.E. Kearns, T. King, T.F. Koinis, J.S. Koontz, M. Kuzma, C. Lindsey, M. Lorentzon, G.P. Lyritis, L.B. Michaud, A. Miciano, S.N. Morin, N. Mujahid, N. Napoli, T.P. Olenginski, J.E. Puzas, S. Rizou, C.J. Rosen, K. Saag, E. Thompson, L.L. Tosi, H. Tracer, S. Khosla, D. Kiel, Secondary Fracture Prevention: Consensus Clinical Recommendations from a Multistakeholder Coalition, J. Bone Miner. Res. 35 (2019) 36-52. https://doi.org/10.1002/jbmr.3877.

[137] E. Toth, J. Banefelt, K. Åkesson, A. Spångeus, G. Ortsäter, C. Libanati, History of Previous Fracture and Imminent Fracture Risk in Swedish Women Aged 55-90 Years Presenting with a Fragility Fracture, J. Bone Miner. Res. (2020) 
jbmr.3953. https://doi.org/10.1002/jbmr.3953.

[138] H.-G. Zmierczak, P. Geusens, S. Poriau, K. De Knop, F. Luyten, FRACTUURPREVENTIE BIJ 50-PLUSSERS: AANBEVELINGEN VAN DE KBVR OSTEOPOROSIS AND FRACTURE PREVENTION WORKING GROUP, OrthoRheumato. 16 (2018) 6-11.

[139] C.M. Parsons, N. Harvey, L. Shepstone, J.A. Kanis, E. Lenaghan, S. Clarke, R. Fordham, N. Gittoes, I. Harvey, R. Holland, N.M. Redmond, A. Howe, T. Marshall, T.J. Peters, D. Torgerson, T.W. O’Neill, E. McCloskey, C. Cooper, N. Crabtree, H. Duffy, J. Parle, F. Rashid, K. Stant, K. Taylor, C. Thomas, E. Knox, C. Tenneson, H. Williams, D. Adams, V. Bion, J. Blacklock, T. Dyer, S. Bratherton, M. Fidler, K. Knight, C. McGurk, K. Smith, S. Young, K. Collins, J. Cushnaghan, C. Arundel, K. Bell, L. Clark, S. Collins, S. Gardner, N. Mitchell, Systematic screening using FRAX ${ }^{\circledR}$ leads to increased use of, and adherence to, anti-osteoporosis medications: an analysis of the UK SCOOP trial, Osteoporos. Int. 31 (2020) 67-75. https://doi.org/10.1007/s00198-019-05142-z.

[140] J.A. Kanis, N.C. Harvey, H. Johansson, E. Liu, L. Vandenput, M. Lorentzon, W.D. Leslie, E. V. McCloskey, A decade of FRAX: how has it changed the management of osteoporosis?, Aging Clin. Exp. Res. 32 (2020) 187-196. https://doi.org/10.1007/s40520-019-01432-y.

[141] J.J. Cao, High Dietary Protein Intake and Protein-Related Acid Load on Bone Health, Curr. Osteoporos. Rep. 15 (2017) 571-576. https://doi.org/10.1007/s11914-017-0408-6.

[142] E. Denova-Gutiérrez, L. Méndez-Sánchez, P. Muñoz-Aguirre, K. Tucker, P. Clark, Dietary Patterns, Bone Mineral Density, and Risk of Fractures: A Systematic Review and Meta-Analysis, Nutrients. 10 (2018) 1922. https://doi.org/10.3390/nu10121922.

[143] R.E. Rikli, C.J. Jones, Development and validation of a functional fitness test for community- residing older adults, J. Aging Phys. Act. 7 (1999) 129-161. https://doi.org/10.1123/japa.7.2.129.

[144] L.M. Giangregorio, S. McGill, J.D. Wark, J. Laprade, A. Heinonen, M.C. Ashe, N.J. MacIntyre, A.M. Cheung, K. Shipp, H. Keller, R. Jain, A. Papaioannou, Too Fit To Fracture: outcomes of a Delphi consensus process on physical activity and exercise recommendations for adults with osteoporosis with or without vertebral fractures, Osteoporos. Int. 26 (2015) 891-910. https://doi.org/10.1007/s00198-014-2881-4.

[145] A.N.A. Tosteson, L.J. Melton, B. Dawson-Hughes, S. Baim, M.J. Favus, S. Khosla, R.L. Lindsay, Cost-effective osteoporosis treatment thresholds: The United States perspective, Osteoporos. Int. 19 (2008) 437-447. https://doi.org/10.1007/s00198-007-0550-6

[146] F. Malgo, N.A.T.T. Hamdy, C.H.J.M.J.M. Ticheler, F. Smit, H.M. Kroon, T.J. Rabelink, O.M. Dekkers, N.M. AppelmanDijkstra, Value and potential limitations of vertebral fracture assessment (VFA) compared to conventional spine radiography: experience from a fracture liaison service (FLS) and a meta-analysis, Osteoporos. Int. 28 (2017) 2955-2965. https://doi.org/10.1007/s00198-017-4137-6.

[147] E. McCloskey, J.A. Kanis, H. Johansson, N. Harvey, A. Odén, A. Cooper, C. Cooper, R.M. Francis, D.M. Reid, D. Marsh P. Selby, F. Thompson, S. Hewitt, J. Compston, FRAX-based assessment and intervention thresholds—an exploration of thresholds in women aged 50 years and older in the UK, Osteoporos. Int. 26 (2015) 2091-2099. https://doi.org/10.1007/s00198-015-3176-0.

[148] E. Shevroja, B. Aubry-Rozier, G. Hans, E.G. Rodriguez, D. Stoll, O. Lamy, D. Hans, Clinical Performance of the Updated Trabecular Bone Score (TBS) Algorithm, Which Accounts for the Soft Tissue Thickness: The OsteoLaus Study, J. Bone Miner. Res. 34 (2019) 2229-2237. https://doi.org/10.1002/jbmr.3851.

[149] J. Bauer, G. Biolo, T. Cederholm, M. Cesari, A.J. Cruz-Jentoft, J.E. Morley, S. Phillips, C. Sieber, P. Stehle, D. Teta, R. Visvanathan, E. Volpi, Y. Boirie, Evidence-based recommendations for optimal dietary protein intake in older people: A position paper from the prot-age study group, J. Am. Med. Dir. Assoc. 14 (2013) 542-559. https://doi.org/10.1016/j.jamda.2013.05.021.

[150] R. Rizzoli, J.C. Stevenson, J.M. Bauer, L.J.C. Van Loon, S. Walrand, J.A. Kanis, C. Cooper, M.-L.L. Brandi, A. DiezPerez, J.-Y.Y. Reginster, ESCEO Task Force, The role of dietary protein and vitamin D in maintaining musculoskeletal health in postmenopausal women: A consensus statement from the European Society for Clinical and Economic Aspects of Osteoporosis and Osteoarthritis (ESCEO), Maturitas. 79 (2014) 122-132. https://doi.org/10.1016/j.maturitas.2014.07.005

[151] D. Sanchez-Rodriguez, L. Lengelé, C. Beaudart, J.-Y. Reginster, O. Bruyère, The Role of Nutrition in Bone Health, in: Dennison, Osteoporos. Treat. A Clin. Overv., 2020: p. In press.

[152] D.M. Black, J.A. Cauley, R. Wagman, K. Ensrud, H.A. Fink, T.A. Hillier, L.-Y. Lui, S.R. Cummings, J.T. Schousboe, N Napoli, The Ability of a Single BMD and Fracture History Assessment to Predict Fracture Over 25 Years in Postmenopausal Women: The Study of Osteoporotic Fractures., J. Bone Miner. Res. 33 (2018) 389-395. https://doi.org/10.1002/jbmr.3194

[153] E. V. McCloskey, A. Odén, N.C. Harvey, W.D. Leslie, D. Hans, H. Johansson, R. Barkmann, S. Boutroy, J. Brown, R. Chapurlat, P.J.M. Elders, Y. Fujita, C.C. Glüer, D. Goltzman, M. Iki, M. Karlsson, A. Kindmark, M. Kotowicz, N. Kurumatani, T. Kwok, O. Lamy, J. Leung, K. Lippuner, Ö. Ljunggren, M. Lorentzon, D. Mellström, T. Merlijn, L. Oei, C. Ohlsson, J.A. Pasco, F. Rivadeneira, B. Rosengren, E. Sornay-Rendu, P. Szulc, J. Tamaki, J.A. Kanis, A Meta-Analysis of Trabecular Bone Score in Fracture Risk Prediction and Its Relationship to FRAX, J. Bone Miner. Res. 31 (2016) 940-948. https://doi.org/10.1002/jbmr.2734.

[154] E.J. Samelson, K.E. Broe, H. Xu, L. Yang, S. Boyd, E. Biver, P. Szulc, J. Adachi, S. Amin, E. Atkinson, C. Berger, L. Burt, 
R. Chapurlat, T. Chevalley, S. Ferrari, D. Goltzman, D.A. Hanley, M.T. Hannan, S. Khosla, C.T. Liu, M. Lorentzon, D. Mellstrom, B. Merle, M. Nethander, R. Rizzoli, E. Sornay-Rendu, B. Van Rietbergen, D. Sundh, A.K.O. Wong, C. Ohlsson, S. Demissie, D.P. Kiel, M.L. Bouxsein, Cortical and trabecular bone microarchitecture as an independent predictor of incident fracture risk in older women and men in the Bone Microarchitecture International Consortium (BoMIC): a prospective study, Lancet Diabetes Endocrinol. 7 (2019) 34-43. https://doi.org/10.1016/S22138587(18)30308-5.

[155] I.R. Reid, A.M. Horne, B. Mihov, A. Stewart, E. Garratt, S. Wong, K.R. Wiessing, M.J. Bolland, S. Bastin, G.D. Gamble, Fracture prevention with zoledronate in older women with osteopenia, N. Engl. J. Med. 379 (2018) 2407-2416. https://doi.org/10.1056/NEJMoa1808082.

[156] H.T. Mai, T.S. Tran, T.P. Ho-Le, J.R. Center, J.A. Eisman, T. V Nguyen, Two-Thirds of All Fractures Are Not Attributable to Osteoporosis and Advancing Age: Implications for Fracture Prevention, J. Clin. Endocrinol. Metab. 104 (2019) 35143520. https://doi.org/10.1210/jc.2018-02614.

[157] A. Cranney, S.A. Jamal, J.F. Tsang, R.G. Josse, W.D. Leslie, Low bone mineral density and fracture burden in postmenopausal women, CMAJ. 177 (2007) 575-580. https://doi.org/10.1503/cmaj.070234.

[158] S.A. Wainwright, L.M. Marshall, K.E. Ensrud, J.A. Cauley, D.M. Black, T.A. Hillier, M.C. Hochberg, M.T. Vogt, E.S. Orwoll, Hip fracture in women without osteoporosis, J. Clin. Endocrinol. Metab. 90 (2005) 2787-2793. https://doi.org/10.1210/jc.2004-1568.

[159] A. Balasubramanian, J. Zhang, L. Chen, D. Wenkert, S.G. Daigle, A. Grauer, J.R. Curtis, Risk of subsequent fracture after prior fracture among older women, Osteoporos. Int. 30 (2019) 79-92. https://doi.org/10.1007/s00198-018-4732-1.

[160] L. Shepstone, E. Lenaghan, C. Cooper, S. Clarke, R. Fong-Soe-Khioe, R. Fordham, N. Gittoes, I. Harvey, N. Harvey, A Heawood, R. Holland, A. Howe, J. Kanis, T. Marshall, T. O’Neill, T. Peters, N. Redmond, D. Torgerson, D. Turner, E. McCloskey, N. Crabtree, H. Duffy, J. Parle, F. Rashid, K. Stant, K. Taylor, C. Thomas, E. Knox, C. Tenneson, H. Williams, D. Adams, V. Bion, J. Blacklock, T. Dyer, S. Bratherton, M. Fidler, K. Knight, C. McGurk, K. Smith, S. Young, K. Collins, J. Cushnaghan, C. Arundel, K. Bell, L. Clark, S. Collins, S. Gardner, N. Mitchell, L. Shepstone, E. Lenaghan, C. Cooper, S. Clarke, R. Fong-Soe-Khioe, R. Fordham, N. Gittoes, I. Harvey, N. Harvey, A. Heawood, R. Holland, A. Howe, J. Kanis, T. Marshall, T. O’Neill, T. Peters, N. Redmond, D. Torgerson, D. Turner, E. McCloskey, N. Crabtree, H. Duffy, J. Parle, F. Rashid, K. Stant, K. Taylor, C. Thomas, E. Knox, C. Tenneson, H. Williams, D. Adams, V. Bion, J. Blacklock, T. Dyer, S. Bratherton, M. Fidler, K. Knight, C. McGurk, K. Smith, S. Young, K. Collins, J. Cushnaghan, C. Arundel, K. Bell, L. Clark, S. Collins, S. Gardner, N. Mitchell, Screening in the community to reduce fractures in older women (SCOOP): a randomised controlled trial, Lancet. 391 (2018) 741-747. https://doi.org/10.1016/S01406736(17)32640-5.

[161] J.A. Kanis, H. Johansson, A. Odén, N.C. Harvey, V. Gudnason, K.M. Sanders, G. Sigurdsson, K. Siggeirsdottir, L.A Fitzpatrick, F. Borgström, E. V. McCloskey, Characteristics of recurrent fractures, Osteoporos. Int. 29 (2018) 1747-1757. https://doi.org/10.1007/s00198-018-4502-0.

[162] H. Johansson, K. Siggeirsdóttir, N.C. Harvey, A. Odén, V. Gudnason, E. McCloskey, G. Sigurdsson, J.A. Kanis, Imminent risk of fracture after fracture, Osteoporos. Int. 28 (2017) 775-780. https://doi.org/10.1007/s00198-016-3868-0.

[163] E.S. Siris, R. Adler, J. Bilezikian, M. Bolognese, B. Dawson-Hughes, M.J. Favus, S.T. Harris, S.M. Jan De Beur, S. Khosla, N.E. Lane, R. Lindsay, A.D. Nana, E.S. Orwoll, K. Saag, S. Silverman, N.B. Watts, The clinical diagnosis of osteoporosis: A position statement from the National Bone Health Alliance Working Group, Osteoporos. Int. 25 (2014) 1439-1443. https://doi.org/10.1007/s00198-014-2655-z.

[164] W.D. Leslie, S.N. Morin, P. Martineau, M. Bryanton, L.M. Lix, Association of Bone Density Monitoring in Routine Clinical Practice With Anti-Osteoporosis Medication Use and Incident Fractures: A Matched Cohort Study, J. Bone Miner. Res. 34 (2019) 1808-1814. https://doi.org/10.1002/jbmr.3813.

[165] A. Diez-Perez, J.D. Adachi, D. Agnusdei, J.P. Bilezikian, J.E. Compston, S.R. Cummings, R. Eastell, E.F. Eriksen, J. Gonzalez-Macias, U.A. Liberman, D.A. Wahl, E. Seeman, J.A. Kanis, C. Cooper, Treatment failure in osteoporosis, Osteoporos. Int. 23 (2012) 2769-2774. https://doi.org/10.1007/s00198-012-2093-8.

[166] J.D. Adachi, C. Berger, R. Barron, D. Weycker, T.P. Anastassiades, K.S. Davison, D.A. Hanley, G. Ioannidis, S.A. Jackson, R.G. Josse, S.M. Kaiser, C.S. Kovacs, W.D. Leslie, S.N. Morin, A. Papaioannou, J.C. Prior, E. Shyta, A. Silvia, T. Towheed, D. Goltzman, Predictors of imminent non-vertebral fracture in elderly women with osteoporosis, low bone mass, or a history of fracture, based on data from the population-based Canadian Multicentre Osteoporosis Study (CaMos), Arch. Osteoporos. 14 (2019). https://doi.org/10.1007/s11657-019-0598-x.

[167] R. Zhao, F. Feng, X. Wang, Exercise interventions and prevention of fall-related fractures in older people: A meta-analysis of randomized controlled trials, Int. J. Epidemiol. 46 (2017) 149-161. https://doi.org/10.1093/ije/dyw142.

[168] W. Kemmler, L. Häberle, S. von Stengel, Effects of exercise on fracture reduction in older adults, Osteoporos. Int. 24 (2013) 1937-1950. https://doi.org/10.1007/s00198-012-2248-7.

[169] A. Moayyeri, The Association Between Physical Activity and Osteoporotic Fractures: A Review of the Evidence and Implications for Future Research, Ann. Epidemiol. 18 (2008) 827-835. https://doi.org/10.1016/j.annepidem.2008.08.007.

[170] J.M. Guirguis-Blake, Y.L. Michael, L.A. Perdue, E.L. Coppola, T.L. Beil, Interventions to prevent falls in older adults: Updated evidence report and systematic review for the US Preventive Services Task Force, JAMA - J. Am. Med. Assoc. 319 (2018) 1705-1716. https://doi.org/10.1001/jama.2017.21962.

[171] T. Merlijn, K.M.A.M. Swart, N.M. van Schoor, M.W. Heymans, B.C. van der Zwaard, A.A. van der Heijden, F. Rutters, P. 
Lips, H.E. van der Horst, C. Niemeijer, J.C. Netelenbos, P.J.M.J. Elders, N.M. Schoor, M.W. Heymans, B.C. Zwaard, A.A. Heijden, F. Rutters, P. Lips, H.E. Horst, C. Niemeijer, J.C. Netelenbos, P.J.M.J. Elders, The Effect of a Screening and Treatment Program for the Prevention of Fractures in Older Women: A Randomized Pragmatic Trial, J. Bone Miner. Res. 34 (2019) 1993-2000. https://doi.org/10.1002/jbmr.3815.

[172] A. V. Hernandez, F.R. Pérez-López, A. Piscoya, V. Pasupuleti, Y.M. Roman, P. Thota, A. Herrera, Comparative efficacy of bone anabolic therapies in women with postmenopausal osteoporosis: A systematic review and network meta-analysis of randomized controlled trials, Maturitas. 129 (2019) 12-22. https://doi.org/10.1016/j.maturitas.2019.08.003.

[173] D.C. Bauer, D.M. Black, M.L. Bouxsein, L.Y. Lui, J.A. Cauley, A.E. de Papp, A. Grauer, S. Khosla, C.E. McCulloch, R. Eastell, Treatment-Related Changes in Bone Turnover and Fracture Risk Reduction in Clinical Trials of Anti-Resorptive Drugs: A Meta-Regression, J. Bone Miner. Res. 33 (2018) 634-642. https://doi.org/10.1002/jbmr.3355.

[174] M.L. Bouxsein, R. Eastell, L.Y. Lui, L.A. Wu, A.E. de Papp, A. Grauer, F. Marin, J.A. Cauley, D.C. Bauer, D.M. Black, Change in Bone Density and Reduction in Fracture Risk: A Meta-Regression of Published Trials, J. Bone Miner. Res. 34 (2019) 632-642. https://doi.org/10.1002/jbmr.3641.

[175] S.R. Cummings, F. Cosman, E.M. Lewiecki, J.T. Schousboe, D.C. Bauer, D.M. Black, T.D. Brown, A.M. Cheung, K Cody, C. Cooper, A. Diez-Perez, R. Eastell, P. Hadji, T. Hosoi, S. Jan De Beur, R. Kagan, D.P. Kiel, I.R. Reid, D.H. Solomon, S. Randall, Goal-Directed Treatment for Osteoporosis: A Progress Report From the ASBMR-NOF Working Group on Goal-Directed Treatment for Osteoporosis, J. Bone Miner. Res. 32 (2017) 3-10. https://doi.org/10.1002/jbmr.3039.

[176] K.T. Borer, K. Fogleman, M. Gross, J.M. La New, D. Dengel, Walking intensity for postmenopausal bone mineral preservation and accrual, Bone. 41 (2007) 713-721. https://doi.org/10.1016/j.bone.2007.06.009.

[177] K.T. Borer, Physical Activity in the Prevention and Amelioration of Osteoporosis in Women, Sport. Med. 35 (2005) 779830. https://doi.org/10.2165/00007256-200535090-00004.

[178] D.M. Black, I.R. Reid, J.A. Cauley, F. Cosman, P.C. Leung, P. Lakatos, K. Lippuner, S.R. Cummings, T.F. Hue, A. Mukhopadhyay, M. Tan, R.P. Aftring, R. Eastell, The effect of 6 versus 9 years of zoledronic acid treatment in osteoporosis: a randomized second extension to the HORIZON-Pivotal Fracture Trial (PFT)., J. Bone Miner. Res. 30 (2015) 934-44. https://doi.org/10.1002/jbmr.2442.

[179] R.A. Adler, G. El-Hajj Fuleihan, D.C. Bauer, P.M. Camacho, B.L. Clarke, G.A. Clines, J.E. Compston, M.T. Drake, B.J. Edwards, M.J. Favus, S.L. Greenspan, R. McKinney, R.J. Pignolo, D.E. Sellmeyer, Managing Osteoporosis in Patients on Long-Term Bisphosphonate Treatment: Report of a Task Force of the American Society for Bone and Mineral Research, J. Bone Miner. Res. 31 (2016) 16-35. https://doi.org/10.1002/jbmr.2708.

[180] D.M. Black, I.R. Reid, S. Boonen, C. Bucci-Rechtweg, J.A. Cauley, F. Cosman, S.R. Cummings, T.F. Hue, K. Lippuner, P. Lakatos, P.C. Leung, Z. Man, R.L.M. Martinez, M. Tan, M.E. Ruzycky, G. Su, R. Eastell, The effect of 3 versus 6 years of Zoledronic acid treatment of osteoporosis: A randomized extension to the HORIZON-Pivotal Fracture Trial (PFT), J. Bone Miner. Res. 27 (2012) 243-254. https://doi.org/10.1002/jbmr.1494.

[181] D.M. Black, A. V. Schwartz, K.E. Ensrud, J.A. Cauley, S. Levis, S.A. Quandt, S. Satterfield, R.B. Wallace, D.C. Bauer, L. Palermo, L.E. Wehren, A. Lombardi, A.C. Santora, S.R. Cummings, Effects of continuing or stopping alendronate after 5 years of treatment: The Fracture Intervention Trial long-term extension (FLEX): A randomized trial, J. Am. Med. Assoc. 296 (2006) 2927-2938. https://doi.org/10.1001/jama.296.24.2927.

[182] K.H. Rubin, M.J. Rothmann, T. Holmberg, M. Høiberg, S. Möller, R. Barkmann, C.C. Glüer, A.P. Hermann, M. Bech, J. Gram, K. Brixen, Effectiveness of a two-step population-based osteoporosis screening program using FRAX: the randomized Risk-stratified Osteoporosis Strategy Evaluation (ROSE) study, Osteoporos. Int. 29 (2018) 567-578. https://doi.org/10.1007/s00198-017-4326-3.

[183] A. V. Schwartz, D.C. Bauer, S.R. Cummings, J.A. Cauley, K.E. Ensrud, L. Palermo, R.B. Wallace, M.C. Hochberg, A.C. Feldstein, A. Lombardi, D.M. Black, Efficacy of continued alendronate for fractures in women with and without prevalent vertebral fracture: The FLEX trial, J. Bone Miner. Res. 25 (2010) 976-982. https://doi.org/10.1002/jbmr.11.

[184] E.M. Lewiecki, N. Binkley, J.P. Bilezikian, Treated Osteoporosis Is Still Osteoporosis, J. Bone Miner. Res. 34 (2019) e3671. https://doi.org/10.1002/jbmr.3671.

[185] M.L. Gourlay, R.A. Overman, J.P. Fine, K.E. Ensrud, C.J. Crandall, M.L. Gass, J. Robbins, K.C. Johnson, E.S. Leblanc, C.R. Womack, J.T. Schousboe, A.Z. Lacroix, Baseline age and time to major fracture in younger postmenopausal women, Menopause. 22 (2015) 589-597. https://doi.org/10.1097/GME.0000000000000356.

[186] A.L. Jensen, K. Lomborg, G. Wind, B.L. Langdahl, Effectiveness and characteristics of multifaceted osteoporosis group education-a systematic review, Osteoporos. Int. 25 (2014) 1209-1224. https://doi.org/10.1007/s00198-013-2573-5.

[187] J.-C. Morfeld, V. Vennedey, D. Müller, D. Pieper, S. Stock, Patient education in osteoporosis prevention: a systematic review focusing on methodological quality of randomised controlled trials, Osteoporos. Int. 28 (2017) 1779-1803. https://doi.org/10.1007/s00198-017-3946-y.

[188] A.C. Ross, J.E. Manson, S.A. Abrams, J.F. Aloia, P.M. Brannon, S.K. Clinton, R.A. Durazo-Arvizu, J.C. Gallagher, R.L. Gallo, G. Jones, C.S. Kovacs, S.T. Mayne, C.J. Rosen, S.A. Shapses, The 2011 Report on Dietary Reference Intakes for Calcium and Vitamin D from the Institute of Medicine: What Clinicians Need to Know, J. Clin. Endocrinol. Metab. 96 (2011) 53-58. https://doi.org/10.1210/jc.2010-2704.

[189] M.F. Holick, N.C. Binkley, H.A. Bischoff-Ferrari, C.M. Gordon, D.A. Hanley, R.P. Heaney, M.H. Murad, C.M. Weaver, 
Evaluation, Treatment, and Prevention of Vitamin D Deficiency: an Endocrine Society Clinical Practice Guideline, J. Clin. Endocrinol. Metab. 96 (2011) 1911-1930. https://doi.org/10.1210/jc.2011-0385.

[190] R. Bouillon, N.M. Van Schoor, E. Gielen, S. Boonen, C. Mathieu, D. Vanderschueren, P. Lips, Optimal vitamin D status: A critical analysis on the basis of evidence-based medicine, J. Clin. Endocrinol. Metab. 98 (2013) E1283-304. https://doi.org/10.1210/jc.2013-1195.

[191] H.N. Rosen, T.J. Vokes, A.O. Malabanan, C.L. Deal, J.D. Alele, T.P. Olenginski, J.T. Schousboe, The Official Positions of the International Society for Clinical Densitometry: Vertebral Fracture Assessment, J. Clin. Densitom. 16 (2013) 482-488. https://doi.org/10.1016/j.jocd.2013.08.003.

[192] M.A. Bass, A. Sharma, V.K. Nahar, S. Chelf, B. Zeller, L. Pham, M.A. Ford, Bone mineral density among men and women aged 35 to 50 years, J. Am. Osteopath. Assoc. 119 (2019) 357-363. https://doi.org/10.7556/jaoa.2019.064.

[193] J.A. Kanis, J.A. Kanis, Assessment of fracture risk and its application to screening for postmenopausal osteoporosis: Synopsis of a WHO report, Osteoporos. Int. 4 (1994) 368-381. https://doi.org/10.1007/BF01622200.

[194] T. Merlijn, K.M.A. Swart, H.E. van der Horst, J.C. Netelenbos, P.J.M. Elders, Fracture prevention by screening for high fracture risk: a systematic review and meta-analysis, Osteoporos. Int. (2019). https://doi.org/10.1007/s00198-019-05226W.

[195] J.T. Schousboe, L.M. Lix, S.N. Morin, S. Derkatch, M. Bryanton, M. Alhrbi, W.D. Leslie, Vertebral Fracture Assessment Increases Use of Pharmacologic Therapy for Fracture Prevention in Clinical Practice, J. Bone Miner. Res. (2019). https://doi.org/10.1002/jbmr.3836.

[196] H.G. Bone, R.B. Wagman, M.L. Brandi, J.P. Brown, R. Chapurlat, S.R. Cummings, E. Czerwiński, A. Fahrleitner-Pammer, D.L. Kendler, K. Lippuner, J.Y. Reginster, C. Roux, J. Malouf, M.N. Bradley, N.S. Daizadeh, A. Wang, P. Dakin, N. Pannacciulli, D.W. Dempster, S. Papapoulos, 10 years of denosumab treatment in postmenopausal women with osteoporosis: results from the phase 3 randomised FREEDOM trial and open-label extension, Lancet Diabetes Endocrinol. 5 (2017) 513-523. https://doi.org/10.1016/S2213-8587(17)30138-9.

[197] S. Lou, H. Lv, G. Wang, Z. Li, M. Li, L. Zhang, P. Tang, The effect of sequential therapy for postmenopausal women with osteoporosis A PRISMA-compliant meta-analysis of randomized controlled trials, Med. (United States). 95 (2016) e5496. https://doi.org/10.1097/MD.0000000000005496.

[198] E. Gielen, P. Bergmann, O. Bruyère, E. Cavalier, P. Delanaye, S. Goemaere, J.-M. Kaufman, M. Locquet, J.-Y. Reginster, S. Rozenberg, A.-M. Vandenbroucke, J.-J. Body, Osteoporosis in Frail Patients: A Consensus Paper of the Belgian Bone Club., Calcif. Tissue Int. 101 (2017) 111-131. https://doi.org/10.1007/s00223-017-0266-3.

[199] L. Oei, F. Koromani, S.J. Breda, J.T. Schousboe, E.M. Clark, J.B.J. van Meurs, M.A. Ikram, J.H. Waarsing, F.J.A. van Rooij, M.C. Zillikens, G.P. Krestin, E.H.G. Oei, F. Rivadeneira, Osteoporotic Vertebral Fracture Prevalence Varies Widely Between Qualitative and Quantitative Radiological Assessment Methods: The Rotterdam Study, J. Bone Miner. Res. 33 (2018) 560-568. https://doi.org/10.1002/jbmr.3220.

[200] J. Banefelt, K.E. Åkesson, A. Spångéus, O. Ljunggren, L. Karlsson, O. Ström, G. Ortsäter, C. Libanati, E. Toth, Risk of imminent fracture following a previous fracture in a Swedish database study, Osteoporos. Int. 30 (2019) 601-609. https://doi.org/10.1007/s00198-019-04852-8.

[201] R. Pinedo-Villanueva, M. Charokopou, E. Toth, K. Donnelly, C. Cooper, D. Prieto-Alhambra, C. Libanati, M.K. Javaid, Imminent fracture risk assessments in the UK FLS setting: implications and challenges, Arch. Osteoporos. 14 (2019) 12 https://doi.org/10.1007/s11657-019-0569-2

[202] E.O. Billington, L.A. Burt, M.S. Rose, E.M. Davison, S. Gaudet, M. Kan, S.K. Boyd, D.A. Hanley, Safety of High-Dose Vitamin D Supplementation: Secondary Analysis of a Randomized Controlled Trial, J. Clin. Endocrinol. Metab. (2019). https://doi.org/10.1210/clinem/dgz212.

[203] M. Lunt, T.W. O’Neill, D. Felsenberg, J. Reeve, J.A. Kanis, C. Cooper, A.J. Silman, G. Armbrecht, W. Gowin, W. Cockerill, J.D. Finn, S. Pye, C. Matthis, H.H. Raspe, D. Banzer, L.I. Benevolenskaya, A. Bhalla, J.B. Cannata, J. Dequeker, R. Eastell, B. Felsch, J. Franke, C. Gennari, S. Havelka, K. Hoszowski, I. Jajic, J. Janott, O. Johnell, A. Lopes Vaz, R. Lorenc, G. Lyritis, P. Masaryk, T. Miazgowski, H.A.P. Pols, G. Poor, D.M. Reid, W. Reisinger, C. Scheidt-Nave, J.J. Stepan, C.J. Todd, K. Weber, A.D. Woolf, Characteristics of a prevalent vertebral deformity predict subsequent vertebral fracture: Results from the European Prospective Osteoporosis Study (EPOS), Bone. 33 (2003) 505-513. https://doi.org/10.1016/S8756-3282(03)00248-5.

[204] H. Johansson, J.A. Kanis, E. V. McCloskey, A. Odén, J.P. Devogelaer, J.M. Kaufman, A. Neuprez, M. Hiligsmann, O Bruyere, J.Y. Reginster, A FRAX ${ }^{\circledR}$ model for the assessment of fracture probability in Belgium, Osteoporos. Int. 22 (2011) 453-461. https://doi.org/10.1007/s00198-010-1218-1.

[205] A. Gómez-Cabello, I. Ara, A. González-Agüero, J.A. Casajús, G. Vicente-Rodríguez, Effects of Training on Bone Mass in Older Adults, Sport. Med. 42 (2012) 301-325. https://doi.org/10.2165/11597670-000000000-00000.

[206] S. Hopewell, O. Adedire, B.J. Copsey, G.J. Boniface, C. Sherrington, L. Clemson, J.C.T. Close, S.E. Lamb, Multifactoria and multiple component interventions for preventing falls in older people living in the community, Cochrane Database Syst. Rev. 2018 (2018). https://doi.org/10.1002/14651858.CD012221.pub2.

[207] I.D. Cameron, S.M. Dyer, C.E. Panagoda, G.R. Murray, K.D. Hill, R.G. Cumming, N. Kerse, Interventions for preventing falls in older people in care facilities and hospitals, Cochrane Database Syst. Rev. 2018 (2018). https://doi.org/10.1002/14651858.CD005465.pub4. 
[208] S. Boonen, J.D. Adachi, Z. Man, S.R. Cummings, K. Lippuner, O. Törring, J.C. Gallagher, J. Farrerons, A. Wang, N. Franchimont, J. San Martin, A. Grauer, M. McClung, Treatment with denosumab reduces the incidence of new vertebral and hip fractures in postmenopausal women at high risk, J. Clin. Endocrinol. Metab. 96 (2011) 1727-1736. https://doi.org/10.1210/jc.2010-2784.

[209] S. Boonen, D.M. Black, C.S. Colón-Emeric, R. Eastell, J.S. Magaziner, E.F. Eriksen, P. Mesenbrink, P. Haentjens, K.W. Lyles, Efficacy and safety of a once-yearly intravenous zoledronic acid $5 \mathrm{mg}$ for fracture prevention in elderly postmenopausal women with osteoporosis aged 75 and older, J. Am. Geriatr. Soc. 58 (2010) 292-299. https://doi.org/10.1111/j.1532-5415.2009.02673.x.

[210] F. Cosman, D.B. Crittenden, S. Ferrari, E.M. Lewiecki, J. Jaller-Raad, C. Zerbini, C.E. Milmont, P.D. Meisner, C. Libanati, A. Grauer, Romosozumab FRAME Study: A Post Hoc Analysis of the Role of Regional Background Fracture Risk on Nonvertebral Fracture Outcome, J. Bone Miner. Res. 33 (2018) 1407-1416. https://doi.org/10.1002/jbmr.3439.

[211] M. Sinaki, B.A. Mikkelsen, A. Beth, Postmenopausal spinal osteoporosis: Flexion versus extension exercises, Arch. Phys. Med. Rehabil. 65 (1984) 593-596.

[212] P.D. Delmas, B. Vrijens, R. Eastell, C. Roux, H.A.P. Pols, J.D. Ringe, A. Grauer, D. Cahall, N.B. Watts, Effect of monitoring bone turnover markers on persistence with risedronate treatment of postmenopausal osteoporosis, J. Clin. Endocrinol. Metab. 92 (2007) 1296-1304. https://doi.org/10.1210/jc.2006-1526.

[213] F. Baleanu, P. Bergmann, A.S. Hambye, C. Dekelver, L. Iconaru, S.I. Cappelle, M. Moreau, M. Paesmans, R. Karmali, J. Body, Assessment of bone quality with trabecular bone score in type 2 diabetes mellitus: A study from the FRISBEE cohort, Int. J. Clin. Pract. 73 (2019) e13347. https://doi.org/10.1111/ijcp.13347.

[214] B.L. Langdahl, C. Libanati, D.B. Crittenden, M.A. Bolognese, J.P. Brown, N.S. Daizadeh, E. Dokoupilova, K. Engelke, J.S. Finkelstein, H.K. Genant, S. Goemaere, L. Hyldstrup, E. Jodar-Gimeno, T.M. Keaveny, D. Kendler, P. Lakatos, J. Maddox, J. Malouf, F.E. Massari, J.F. Molina, M.R. Ulla, A. Grauer, Romosozumab (sclerostin monoclonal antibody) versus teriparatide in postmenopausal women with osteoporosis transitioning from oral bisphosphonate therapy: a randomised, open-label, phase 3 trial, Lancet. 390 (2017) 1585-1594. https://doi.org/10.1016/S0140-6736(17)31613-6.

[215] H.K. Genant, C.Y. Wu, C. van Kuijk, M.C. Nevitt, Vertebral fracture assessment using a semiquantitative technique, J. Bone Miner. Res. 8 (1993) 1137-1148. https://doi.org/10.1002/jbmr.5650080915.

[216] P. Geusens, F. Marin, D.L. Kendler, L.A. Russo, C.A. Zerbini, S. Minisola, J.J. Body, E. Lespessailles, S.L. Greenspan, A Bagur, J.J. Stepan, P. Lakatos, E. Casado, R. Moericke, P. López-Romero, A. Fahrleitner-Pammer, Effects of Teriparatide Compared with Risedronate on the Risk of Fractures in Subgroups of Postmenopausal Women with Severe Osteoporosis: The VERO Trial, J. Bone Miner. Res. 33 (2018) 783-794. https://doi.org/10.1002/jbmr.3384.

[217] K.G. Saag, J. Petersen, M.L. Brandi, A.C. Karaplis, M. Lorentzon, T. Thomas, J. Maddox, M. Fan, P.D. Meisner, A Grauer, Romosozumab or Alendronate for Fracture Prevention in Women with Osteoporosis., N. Engl. J. Med. 377 (2017) 1417-1427. https://doi.org/10.1056/NEJMoa1708322.

[218] K.E. Naylor, R.M. Jacques, M. Paggiosi, F. Gossiel, N.F.A. Peel, E. V McCloskey, J.S. Walsh, R. Eastell, Response of bone turnover markers to three oral bisphosphonate therapies in postmenopausal osteoporosis: the TRIO study., Osteoporos. Int. 27 (2016) 21-31. https://doi.org/10.1007/s00198-015-3145-7.

[219] M.A. Paggiosi, N. Peel, E. McCloskey, J.S. Walsh, R. Eastell, Comparison of the effects of three oral bisphosphonate therapies on the peripheral skeleton in postmenopausal osteoporosis: the TRIO study, Osteoporos. Int. 25 (2014) 2729 2741. https://doi.org/10.1007/s00198-014-2817-z.

[220] J.A. Kanis, A. Oden, O. Johnell, H. Johansson, C. De Laet, J. Brown, P. Burckhardt, C. Cooper, C. Christiansen, S. Cummings, J.A. Eisman, S. Fujiwara, C. Glüer, D. Goltzman, D. Hans, M.A. Krieg, A. La Croix, E. McCloskey, D. Mellstrom, L.J. Melton, H. Pols, J. Reeve, K. Sanders, A.M. Schott, A. Silman, D. Torgerson, T. Van Staa, N.B. Watts, N. Yoshimura, The use of clinical risk factors enhances the performance of BMD in the prediction of hip and osteoporotic fractures in men and women, Osteoporos. Int. 18 (2007) 1033-1046. https://doi.org/10.1007/s00198-007-0343-y.

[221] J.A. Eisman, T. V. Nguyen, S.A. Frost, N.D. Nguyen, J.R. Center, Development of a nomogram for individualizing hip fracture risk in men and women, Osteoporos. Int. 18 (2007) 1109-1117. https://doi.org/10.1007/s00198-007-0362-8.

[222] N.D. Nguyen, S.A. Frost, J.R. Center, J.A. Eisman, T. V. Nguyen, Development of prognostic nomograms for individualizing 5-year and 10-year fracture risks, Osteoporos. Int. 19 (2008) 1431-1444. https://doi.org/10.1007/s00198008-0588-0.

[223] J. Hippisley-Cox, C. Coupland, Predicting risk of osteoporotic fracture in men and women in England and Wales: Prospective derivation and validation of QFractureScores, BMJ. 339 (2009) 1291-1295. https://doi.org/10.1136/bmj.b4229.

[224] P.D. Delmas, H.K. Genant, G.G. Crans, J.L. Stock, M. Wong, E. Siris, J.D. Adachi, Severity of prevalent vertebral fractures and the risk of subsequent vertebral and nonvertebral fractures: Results from the MORE trial, Bone. 33 (2003) 522-532. https://doi.org/10.1016/S8756-3282(03)00241-2.

[225] F. Cosman, T.M. Keaveny, D. Kopperdahl, R.A. Wermers, X. Wan, K.D. Krohn, J.H. Krege, Hip and spine strength effects of adding versus switching to teriparatide in postmenopausal women with osteoporosis treated with prior alendronate or raloxifene, J. Bone Miner. Res. 28 (2013) 1328-1336. https://doi.org/10.1002/jbmr.1853.

[226] H. Blain, T. Masud, P. Dargent-Molina, F.C. Martin, E. Rosendahl, N. van der Velde, J. Bousquet, A. Benetos, C. Cooper, J.A. Kanis, J.Y. Reginster, R. Rizzoli, B. Cortet, M. Barbagallo, K.E. Dreinhöfer, B. Vellas, S. Maggi, T. Strandberg, A 
comprehensive fracture prevention strategy in older adults: the European Union Geriatric Medicine Society (EUGMS) statement, Aging Clin. Exp. Res. 28 (2016) 797-803. https://doi.org/10.1007/s40520-016-0588-4.

[227] F. Cosman, J.W. Nieves, D.W. Dempster, Treatment Sequence Matters: Anabolic and Antiresorptive Therapy for Osteoporosis., J. Bone Miner. Res. 32 (2017) 198-202. https://doi.org/10.1002/jbmr.3051.

[228] A. Neuprez, H. Johannson, J.A. Kanis, E. V McCloskey, A. Odén, O. Bruyère, M. Hiligsmann, J. Devogelaer, J. Kaufman, J. Reginster, Rationalisation du remboursement des médicaments de l’ostéoporose : de la mesure isolée de la densité osseuse à l'intégration des facteurs cliniques de risque fracturaire. Validation de l'algorithme FRAX ${ }^{\circledR}$, Rev. Med. Liège. 64 (2009) 612-619.

[229] P. Wang, Y. Li, H. Zhuang, H. Yu, S. Cai, H. Xu, Z. Chen, J. Lin, X. Yao, Influence of bone densitometry on the antiosteoporosis treatment after fragility hip fracture, Aging Clin. Exp. Res. 31 (2019) 1525-1529. https://doi.org/10.1007/s40520-018-1094-7.

[230] W. Xia, C. Cooper, M. Li, L. Xu, R. Rizzoli, M. Zhu, H. Lin, J. Beard, Y. Ding, W. Yu, E. Cavalier, Z. Zhang, J.A. Kanis, Q. Cheng, Q. Wang, J.-Y. Reginster, East meets West: current practices and policies in the management of musculoskeletal aging., Aging Clin. Exp. Res. 31 (2019) 1351-1373. https://doi.org/10.1007/s40520-019-01282-8.

[231] M. Chandran, D. Tay, A. Mithal, Supplemental calcium intake in the aging individual: implications on skeletal and cardiovascular health, Aging Clin. Exp. Res. 31 (2019) 765-781. https://doi.org/10.1007/s40520-019-01150-5.

[232] P. Fardellone, The effect of milk consumption on bone and fracture incidence, an update., Aging Clin. Exp. Res. 31 (2019) 759-764. https://doi.org/10.1007/s40520-019-01192-9.

[233] A. Diez-Perez, M.L. Brandi, N. Al-Daghri, J.C. Branco, O. Bruyère, L. Cavalli, C. Cooper, B. Cortet, B. Dawson-Hughes, H.P. Dimai, S. Gonnelli, P. Hadji, P. Halbout, J.-M.M. Kaufman, A. Kurth, M. Locquet, S. Maggi, R. Matijevic, J.-Y.Y. Reginster, R. Rizzoli, T. Thierry, Radiofrequency echographic multi-spectrometry for the in-vivo assessment of bone strength: state of the art-outcomes of an expert consensus meeting organized by the European Society for Clinical and Economic Aspects of Osteoporosis, Osteoarthritis and Mus, Aging Clin. Exp. Res. 31 (2019) 1375-1389. https://doi.org/10.1007/s40520-019-01294-4.

[234] J.G. Howe, R.S. Hill, J.D. Stroncek, J.L. Shaul, D. Favell, R.R. Cheng, K. Engelke, H.K. Genant, D.C. Lee, T.M. Keaveny, M.L. Bouxsein, B. Huber, Treatment of bone loss in proximal femurs of postmenopausal osteoporotic women with AGN1 local osteo-enhancement procedure (LOEP) increases hip bone mineral density and hip strength: a long-term prospective cohort study., Osteoporos. Int. (2019). https://doi.org/10.1007/s00198-019-05230-0.

[235] I. Iguacel, M.L. Miguel-Berges, A. Gómez-Bruton, L.A. Moreno, C. Julián, Veganism, vegetarianism, bone mineral density, and fracture risk: a systematic review and meta-analysis, Nutr. Rev. 77 (2019) 1-18. https://doi.org/10.1093/nutrit/nuy045.

[236] N. Veronese, J.-Y.Y. Reginster, The effects of calorie restriction, intermittent fasting and vegetarian diets on bone health Aging Clin. Exp. Res. 31 (2019) 753-758. https://doi.org/10.1007/s40520-019-01174-x.

[237] M. Lorentzon, J. Branco, M.L. Brandi, O. Bruyère, R. Chapurlat, C. Cooper, B. Cortet, A. Diez-Perez, S. Ferrari, A. Gasparik, M. Herrmann, N.R. Jorgensen, J. Kanis, J.-M. Kaufman, A. Laslop, M. Locquet, R. Matijevic, E. McCloskey, S. Minisola, R. Pikner, J.-Y. Reginster, R. Rizzoli, P. Szulc, M. Vlaskovska, E. Cavalier, Algorithm for the Use of Biochemical Markers of Bone Turnover in the Diagnosis, Assessment and Follow-Up of Treatment for Osteoporosis, Adv. Ther. 36 (2019) 2811-2824. https://doi.org/10.1007/s12325-019-01063-9.

[238] R. Bouillon, A. Calgari, Safety of high dose vitamin D supplementation, J. Clin. Endocrinol. Metab. (2020)

[239] P. Lips, J.P. Bilezikian, R. Bouillon, Vitamin D: Giveth to Those Who Needeth, JBMR Plus. (2019) e10232. https://doi.org/10.1002/jbm4.10232.

[240] P. Yao, D. Bennett, M. Mafham, X. Lin, Z. Chen, J. Armitage, R. Clarke, Vitamin D and Calcium for the Prevention of Fracture: A Systematic Review and Meta-analysis, JAMA Netw. Open. 2 (2019) e1917789. https://doi.org/10.1001/jamanetworkopen.2019.17789.

[241] D. Eleftheriou, V. Benetou, A. Trichopoulou, C. La Vecchia, C. Bamia, Mediterranean diet and its components in relation to all-cause mortality: Meta-analysis, Br. J. Nutr. 120 (2018) 1081-1097. https://doi.org/10.1017/S0007114518002593.

[242] E. Tsartsou, N. Proutsos, E. Castanas, M. Kampa, Network meta-analysis of metabolic effects of olive-oil in humans shows the importance of olive oil consumption with moderate polyphenol levels as part of the mediterranean diet, Front. Nutr. 6 (2019). https://doi.org/10.3389/fnut.2019.00006

[243] S. Rozenberg, J.-J.J. Body, O. Bruyère, P. Bergmann, M.L. Brandi, C. Cooper, J.-P.P. Devogelaer, E. Gielen, S. Goemaere, J.-M.M. Kaufman, R. Rizzoli, J.-Y.Y. Reginster, Effects of Dairy Products Consumption on Health: Benefits and Beliefs-A Commentary from the Belgian Bone Club and the European Society for Clinical and Economic Aspects of Osteoporosis, Osteoarthritis and Musculoskeletal Diseases., Calcif. Tissue Int. 98 (2016) 1-17. https://doi.org/10.1007/s00223-015-0062-x

[244] H. Malmir, P. Saneei, B. Larijani, A. Esmaillzadeh, Adherence to Mediterranean diet in relation to bone mineral density and risk of fracture: a systematic review and meta-analysis of observational studies, Eur. J. Nutr. 57 (2018) 2147-2160. https://doi.org/10.1007/s00394-017-1490-3.

[245] M.R. McClung, J.P. Brown, A. Diez-Perez, H. Resch, J. Caminis, P. Meisner, M.A. Bolognese, S. Goemaere, H.G. Bone, J.R. Zanchetta, J. Maddox, S. Bray, A. Grauer, Effects of 24 Months of Treatment With Romosozumab Followed by 12 
Months of Denosumab or Placebo in Postmenopausal Women With Low Bone Mineral Density: A Randomized, DoubleBlind, Phase 2, Parallel Group Study, J. Bone Miner. Res. 33 (2018) 1397-1406. https://doi.org/10.1002/jbmr.3452.

[246] J.A. Cauley, L. Norton, M.E. Lippman, S. Eckert, K.A. Krueger, D.W. Purdie, J. Farrerons, A. Karasik, D. Mellstrom, K.W. Ng, J.J. Stepan, T.J. Powles, M. Morrow, A. Costa, S.L. Silfen, E.L. Walls, H. Schmitt, D.B. Muchmore, V.C. Jordan, L.G. Ste-Marie, Continued breast cancer risk reduction in postmenopausal women treated with raloxifene: 4-year results from the MORE trial. Multiple outcomes of raloxifene evaluation., Breast Cancer Res. Treat. 65 (2001) 125-34. https://doi.org/10.1023/a:1006478317173.

[247] E. Cavalier, P. Lukas, B. Michela, A. Aasne, F. Ceriotti, A. Coskun, J. Díaz-Garzón, European Biological Variation Study (EuBIVAS): Within- and between-subject biological variation estimates of C-terminal telopeptides of type I collagen (CTX), N-terminal propeptide of type I collagen (PINP), osteocalcin, intact Fibroblast growth factor 23, (2020) In press.

[248] O. Beauchet, B. Fantino, C. Annweiler, The 'Action-Research’ philosophy: from bedside to bench, to bedside again, Int. J. Clin. Pract. 66 (2012) 517-517. https://doi.org/10.1111/j.1742-1241.2012.02909.x. 